This item was submitted to Loughborough's Research Repository by the author.

Items in Figshare are protected by copyright, with all rights reserved, unless otherwise indicated.

\title{
A new perspective on personas and customer journey maps: Proposing systemic UX
}

PLEASE CITE THE PUBLISHED VERSION

https://doi.org/10.1016/j.ijhcs.2021.102583

PUBLISHER

Elsevier

VERSION

AM (Accepted Manuscript)

\section{PUBLISHER STATEMENT}

This paper was accepted for publication in the journal International Journal of Human Computer Studies and the definitive published version is available at https://doi.org/10.1016/j.ijhcs.2021.102583

LICENCE

CC BY-NC-ND 4.0

\section{REPOSITORY RECORD}

Bradley, C, L Oliveira, S Birrell, and Rebecca Cain. 2021. "A New Perspective on Personas and Customer Journey Maps: Proposing Systemic UX”. Loughborough University. https://hdl.handle.net/2134/14125457.v1. 


\title{
A new perspective on personas and customer journey maps: Proposing systemic UX
}

\section{Authors}

\section{Callum Bradley}

Goldsmiths, University of London, London, SE14 6NW, UK

https://orcid.org/0000-0003-1663-4756

\section{Dr Luis Oliveira}

WMG, University of Warwick, Coventry, CV4 7AL, UK

https://orcid.org/0000-0003-3732-6410

Professor Stewart Birrell (corresponding author)

Institute for Future Transport and Cities, Coventry University, UK

https://orcid.org/0000-0001-8778-4087

\section{Professor Rebecca Cain}

School of Design and Creative Arts, Loughborough University, UK https://orcid.org/0000-0001-9453-0667

\begin{abstract}
This article explores user experience research within a consequentialist philosophical framework, where an optimal design depends on users' resultant levels of satisfaction and pleasure. Personas and customer journey maps can be pragmatic in indicating the requirements of a system by aggregating the overall pleasure of the majority of users. However, a revised approach, focused on minimising displeasures at the expense of reducing the pleasures of others, may level out individuals' satisfactory experiences with a view toward more holistic, systemic satisfaction for all users. We explore our philosophical thinking and illustrate these premises with a project set out to develop technological innovation for the rail industry. We conclude with recommendations of how designers could think about user experience to incorporate systemic views of pleasure when proposing innovations.
\end{abstract}

Keywords: Design methods; innovation; interdisciplinarity; philosophy of design; user experience 


\section{Introduction}

\section{User experience and rail transport}

Models for increasing customer satisfaction are built on designing pleasurable products and providing value-adding services (Kuniavsky et al., 2012). The concept of experience is central to the pursuit of better customer satisfaction. Experience can be defined as an episode or a length of time that one individual goes through (Hassenzahl, 2010), involving tangible perceptions through senses and also feelings and thoughts. User experience (UX) is a very personal phenomenon: what engages and enchants one user may bore or irritate another (Blythe et al., 2006). UX design focuses on interactive products and services that create, facilitate and mediate the process of experiential perception and the resultant satisfaction levels felt by individuals (Hassenzahl, 2010). Interactive products and services that we encounter in our lives have the power to shape what we feel, and will inevitably influence our experience (Hassenzahl and Tractinsky, 2006). Customer satisfaction is highly related to what people expect to receive from the service provider (Zeithaml et al., 1993), hence the importance of evaluating what users need and desire.

Socio-technical systems such as transportation are challenging fields to integrate these ideas into. Design strategies across different modes such as road, rail or air transport show that user perceptions in terms of utility and ease of use are important determinants of uptake and acceptance (Aceves-González et al., 2016; Fei et al., 2016; Kefalidou et al., 2016; L. Oliveira et al., 2019). We build on these concepts of UX design to spur system acceptance, staged in the contextual challenges posed by rail transport. We argue that any kind of systemwide utility not only stems from individual users' feelings of pleasure and ease, but at once relies on an interconnected network whereby users' negative values can impact other users' valuations of a system. In other words, one person's negative experience can damage the total ease of use felt across all users' experiences. This shared staging of interdependent utilities - 
broadly branded as 'systemic' throughout this article - is reflected in our application of personas and customer journey maps that collate and contrast data obtained from multiple users. This work is particularly pertinent to addressing the problems surrounding British rail transport, which otherwise seeks to standardise and conform users' experiences.

Importantly, this reasoning calls into question the credibility of design decisions generally: how, and should we, incorporate into our methods techniques for more fairly and socially-responsibly researching the systemic impacts of designs? This question is in part inspired by pre-existing research, as well as wider conceptions of gender equality, which call for more diverse applications of shared responsibility in designing from a feminine ethics of care (Basart et al., 2015). The present research is grounded in contemporary revisions of traditional philosophy toward better grasping the interconnectedness of users, around care and compassion. Through our methods, these sentiments are organised into concrete nodes, or 'values', that are woven into data collection and the strategies for its presentation. For example, the data puts forward the limits and non-exclusivity of individuals' pleasures, so that one user's experience may well be hampered by encountering and negatively experiencing other users during a journey. This strategy follows previous research that has outlined value-oriented approaches to user research (Pereira and Baranauskas, 2015). Categorising users' values, it is possible to define shared interests and interactive goals across a system, for example, affection, security and adaptability. These terms fit into the wider framework of what this research titles as 'systemic' values, fleshing out the emotional implications of shared user experiences. Moreover, when applying this research to designing with systemic principles in mind, values referring to "cultural particularities" between individuals (Pereira and Baranauskas, 2015, p. 71) can be referred back to for a breakdown of system-wide values that are shared by users in socio-technical systems. 
Design tools are frequently used in the process of improving and developing products and services, allowing people from multiple disciplines to engage in service design (Broberg et al., 2011; Mackrill et al., 2017). One of these tools is the Customer Journey Map, which can provide a graphical representation of users' encounters with products, services or systems. These diagrams present stages of the journey, user actions and emotions at specific times and locations (Stickdorn and Schneider, 2010). They usually display the points of contact with a system, illustrating users' affective responses during interactions. Journey maps are applied in the process of creating new technologies, where designers map problematic touchpoints and determine where innovation can improve or worsen user satisfaction. An apt method for plotting a continuum of experiences throughout a rail journey, the importance attributed to discrete touchpoints in turn signals the extent to which the collective user experiences of rail transport is grounded in shared, interdependent and systems-based events.

Another common design tool, personas are used to represent archetypal users and facilitate the understanding of user behaviours, needs, motivations, characteristics and limitations (Cooper, 1999; Goodwin, 2009). Having a small set of personas can make real users more tangible and facilitate empathy from the development team. Personas can be pragmatic tools for the development of products for specific users and their needs, and help during the prioritisation of product requirements (Miaskiewicz and Kozar, 2011). The resulting proposed product or service should be the one that mostly satisfies users, and developers must allow enough adaptation and customisation so the system is able to "bend and stretch and adapt to the user's needs" (Cooper, 1999, p. 127). Importantly for this project, Oliveira et al. created personas to represent train passengers (2018) and crewmembers facing new technology at work (2020), and Marshall et al. (2015) demonstrated how personas were 
used to evaluate the accessibility of rail transport and indicate failure points involving ticket machines and navigation at stations.

A discussion of these two research methods bears context-based relevance to rail transport, which links empirical insight to theories that mandate a more social and systemic model for UX. This paper seeks to produce a methodological framework that works against the independence of individual consumers' satisfaction. Instead, our methodology frames a more holistic, interrelated system that designs for unified networks of interests and experiences. Central to this is minimising the displeasure felt by any user on the basis that this damages the overall utility and value of a system. This is realised through our philosophical considerations of contemporary utilitarianism, which opens up to broader systemic thinking. Concretising these concepts in our research, we leverage persona-based research, in line with the socio-technical interdependence evidenced in the continuum of mapped experiences shared between any and all users of rail transport. As is usual with product and service design (Maguire, 2001; Stickdorn and Schneider, 2010), our research focuses on consumers, but in addition philosophically observes the possibly invisible needs of a minority of users as part of designing shared and holistic utilities in socio-technical networks.

\section{User experience and consequentialism}

User experience research follows a philosophical logic akin to consequentialism, or that the value of properties depends on the consequential experiences evoked in users. Utilitarianism, a form of consequentialist philosophical logic, originates in the works of Jeremy Bentham and John Stuart Mill. They suggested that an ethically - or efficiently justifiable system depends on the maximisation of individuals' levels of satisfaction and pleasure (Bentham, 1996; Mill, 1864). This calibration is essentially quantitative, and the final calculation is one of deriving net utility felt by the majority of users. However, there are 
many criticisms of utilitarian consequentialism, originating from Bentham's contemporaries in the $19^{\text {th }}$ century (Bentham, 1996), who attacked the unstable and subjective aspect of hedonistic fulfilment. What is pleasurable to one may be a source of pain for another. Quantitative hedonists simply aggregate the pleasures of people within a group, calculating a net utility by adding all people's pleasure and subtracting their pain. This was problematic: not only was there a question of what defined a pleasure and determined it as a unit of measurement for utility, but many highlighted the dynamism and variation amongst one another in what was deemed a pleasurable experience.

A follower of Bentham, Mill's (1864) utilitarianism, then, proposed a revision of higher and lower pleasures. In determining some pleasures as more valuable or higher than others, a qualitative aspect was introduced to the calculation of net utility. This research interrogates what the basis might be for these qualitative evaluations in the UX sphere, resourcing personas and customer journey maps as a method for collating the complexity of human affect in terms of valence and activation (Posner et al., 2005). The problem of hedonistic reasoning still remains: is being calm and serene comparable to being excited and enthusiastic? Are we capable of calculating an aggregation of people's various pleasures, and what determines some of their values to be higher than others? And in our particular case, how can we translate this into our UX research for working through the various and disparate utilities users associate with rail transport?

Since the works of Bentham and Mill, more contemporary philosophers have introduced a variety of debates and additional premises toward defining the optimal form of consequentialist good. Nozick's (2013) imagining of the 'experience machine' thought experiment introduces many of these contemporary concerns. He asks: would people consent to entering a virtual reality machine that engineered an individual's experience of the world to be maximally pleasurable, without any discomfort? We are led to wonder whether an 
individual's consenting decision would be influenced if they were conscious of the machine as virtual reality; the system they occupied would be fictitious, void of other people or agencies beyond the user. Whilst hedonists may select purely sensational pleasures and consent to entering the machine, and whilst Mill may solely be concerned with the qualitative aspects of independent pleasures, contemporary revisions more so focus on propositional pleasures that are dependent upon and invite the agencies of other users and as well as the possibility of accommodating negative sensations within a system (Feldman, 1997). This reformulated kind of consequentialism, termed propositional utilitarianism, can be condensed into the example 'I am happy that you did that for me', whereby my pleasure derives from a certain state of affairs outside of myself, the fact that something was done without me, but positively affects me and thus the system we occupy together.

Through these contemporary revisions of utilitarianism, we can discern a more systemic landscape opening out, through which utility can be thought of more collectively and interdependently, toward care and compassion for other users in a system. Similarly, in UX research, contemporary work should consider whether the most efficient design is justified merely on the basis of each individual's discrete satisfaction. Instead, the maximisation of systemic satisfaction might be better achieved by attending to a holistic set of interrelated needs. Still working toward maximal profit and positive branding, previous research can be observed that advocates for greater attention in the design process to maximising users' affective responses. Particularly, attention is given less to the recognition of discrete product utilities and more so to how such a product contains and coordinates users within a positive relational field - systemic satisfaction. A specific instance of this, pertinent to the current research, recent arguments have suggested the benefits of designing along an "affective path [which] may have more influence than the utilitarian path in facilitating branded app loyalty" (Tseng and Lee, 2018, p. 1307). 
This research seeks to justify the kinds of compromises individual users want (and sometimes need) from profit-seeking rail companies. Handling primary data so as to highlight the importance of systemic needs (modelled after the propositional and preference-based contemporary revisions of utilitarianism), this research leverages customer journey maps and personas as foundations to build a more unified and systemic model of optimal utility across users' experiences of the rail transport system. Following one of the major proponents of systems theory, Gregory Bateson, this paper is informed by his conception of three interrelated systems: the individual, the society and the ecosystem (Bateson, 1972). This research seeks to apply his sentiment that "human consciousness is considered as the coupling of these systems", toward reconfiguring questions of human purpose and adaptation within a systemic "balance[ing] between man, his society and his ecosystem" (Bateson, 1972, p. 446). This sentiment is applied to the field of user experience and the particular design of rail transport services, considering the networking of individuals within socio-technical systems. Moreover, with a specific interest in the introduction of emerging technologies into the rail network, a preliminary cautiousness is guided by Bateson's notion that distortions implemented by modern technology can become destructive of the balances within systems.

\section{Designing for systemic user experiences of rail transport}

The above sections can be specifically contextualised alongside ongoing research into the UXs of rail transport, as this article attends to the specific potentiality for the implementation of emerging technologies to achieve better functionality and customer satisfaction. Technology developments, together with increasing user connectivity and demand for more information (Transport Focus, 2014), present remarkable opportunities to increase the number of features available to passengers. There are opportunities to improve pre-trip, boarding, onboard, post-trip information, fare collection processes and wayfinding guidance in the attempt to improve passengers' experiences (Camacho et al., 2013; Foth and 
Schroeter, 2010; Groff et al., 2014; L. C. Oliveira et al., 2019; Peña Miñano et al., 2017). Framing this with contemporary revisions of utilitarianism, central issues arise regarding the possible struggles and obstacles a minority of users will inevitably face with the increased technologising of a service. There are reports of resistance prior to the adoption of technology, when users consider a range of factors such as ease of use and usefulness, but which are less prominent after continued usage (Karahanna et al., 1999). Other barriers should also be considered, as not all passengers use smartphones, and some of them fear being disadvantaged if other people get lower prices and better services (Transport Focus, 2014).

Travel time can be a gift to the individual traveller, who often is immersed in their own activities during journeys to pass the time (Lyons et al., 2016; Oliveira et al., 2016). However, not all journeys are experienced in quiet comfort: activities of fellow passengers may be a source of distress (Jain and Lyons, 2008; Wardman and Murphy, 2015). Specific demographic groups have more difficulties with certain parts of journeys, for example when boarding or alighting (Aceves-González et al., 2016). On top of this, given the propositional and systemic nature of pleasure and utility, this research further questions the extent to which the minority's displeasure may impact and interrupt the journeys of the majority.

In terms of this specific environment, with a wealth of challenges and criticism currently surroundings issues in rail transport, much of the blame is being placed on the corporatisation of what was once a nationalised sphere. Calculations of costs and benefits guided the British rail privatisation programme, a project with questionable results (Jupe and Funnell, 2017; McCartney and Stittle, 2017). By using a utilitarian approach, it was given the diverse components of the industry accounting values, and entrepreneurial freedom was seen as the solution to bring about improvements to the industry. Benefits proposed by privatisation included lower fares, increased number of passengers transported and improved 
quality of service. However, journeys are being compromised by the increasing crowding (ORR, 2015; Wockatz and Schartau, 2015), there has been a decline in passenger satisfaction over recent years (Lyons et al., 2016), and poor public transport can impact passengers' quality of life and health (Friman et al., 2017).

There appears to be a reliance on technology as a facilitator to improve passenger experience (Transport Committe, 2016), even though the problems surrounding rail transport in the UK seem considerably more complex. The philosophy that arose from these issues was also boosted by the current emphasis on the development of transport services that "take into consideration the greatest diversity of potential end users" (Santana et al., 2018, p. 152). Ethical questions emerged and heightened the need for research and analysis of user experiences of the travelling public.

\section{Aims}

The premises for this article originated from the potential improvements brought about by emerging technology in the pursuit of better products and services for train passengers. As part of a multidisciplinary, academic-industry partnership project, this research was set to critically view UX research in its attempt to inform the requirements of technological innovations. We framed the potentials and promises of technology within a revised utilitarianism that considers the systemic nature of pleasure and utility.

The aim of this article was then to propose the concept of systemic UX as an innovative design approach that attends to the balancing of users' needs and ensuring that minority demographics are not overlooked. Rail transport is focused on as a particularly relevant and challenging context framing these concepts. Design methods of personas and customer journey maps provided the platform for testing these propositions from an integrated standpoint. This writing should be read as a commentary not just on the use of UX research, journey maps and personas, their shortcomings and possible solutions. These 
problems and revisions also reflect the larger philosophical concerns of many people surrounding the direction of individualisation in public service fulfilment, and the ways in which UX research can accommodate and efficiently apply these concerns toward fostering more shared and equal experiences.

\section{Methods}

This research started by collecting and incorporating literature from diverse disciplines to build the core of our argument. Philosophical principles of revised consequentialism (Feldman, 1997) were introduced alongside systems theory, as is commonly applied to the fields of family therapy (Kerr, 1981), and studies of human affect in order to better understand the relations between users (Posner et al., 2005). These disciplines were brought together, creating a system of thought through which questions concerning UX might be better fielded (Kuniavsky et al., 2012). A systemic UX seemed more adequate to evaluate and portray what users of a public service really felt, whilst ensuring significance was not given to certain voices over others, or to the implementation of innovative technologies at the expense of people's shared experiences. We then proceeded to test our propositions by leveraging design research methods as the foundations for validating the viability of our arguments. Customary methods for creating personas (Cooper, 1999; Goodwin, 2009) and customer journey maps (Stickdorn and Schneider, 2010), as described below, were the elements used for this validation. This research received ethical and data protection approval from the Biomedical \& Scientific Research Ethics Committee (BSREC), University of Warwick, under code REGO-2016-1771.

The process for creating personas and designing journey experience maps involved collecting data via two methods: firstly, with interviews and probes in our offices, then with added questionnaires given to rail passengers on board trains (Table 1). 
Table 1 - Participants' demographics

\begin{tabular}{|l|r|r|}
\hline & Interviews & Questionnaires \\
\hline Age & 1 & 17 \\
\hline $18-25$ & 11 & 11 \\
\hline $25-45$ & 8 & 14 \\
\hline $45-60$ & 0 & 6 \\
\hline $60+$ & & 2 \\
\hline Undisclosed & 11 & 23 \\
\hline Gender & 9 & 27 \\
\hline Male & \multicolumn{3}{|}{} \\
\hline Female & 20 & 50 \\
\hline total: & & \\
\hline
\end{tabular}

\section{Interviews}

A convenience sampling strategy was used, and the recruitment of passengers for interviews was conducted through emails sent to the University of Warwick employees. Those who had travelled by train recently were invited to take part in an interview containing a variety of open-ended questions to describe their train journeys and express their opinions. Twenty participants (eleven male) took part in the interviews, which were of approximately 25 minutes in length on average. The qualitative data collected from interviews, with the use of a voice recorder, therefore totalled around 8.5 hours in length.

\section{Materials and procedure}

We asked participants to fill in cultural probes (Hutchinson et al., 2003) such as rating scales, perform a manual ranking activity, and answer semi-structured questions, as detailed in Table 2. These probes included blank tables in which our seven allotted journey touchpoints were correlated against 5-point rankings, ranging from a +2 to a -2 emotional response on happy and sad faces (Figure 1). Participants were asked to describe their recent travels in relation to seven common touchpoints in the rail system, namely, to plan and buy tickets, collect tickets, navigate stations, board trains, locate their seats, validate their tickets, 
and alight. These touchpoints presented were generated by combining examples from the literature review (Aceves-González et al., 2015; Oliveira et al., 2017; L. C. Oliveira et al., 2020; van Hagen and Bron, 2014) collated into a more manageable number of key journey stages. Touchpoints worked as prompts, helping passengers to recollect and describe the sequential events they experience during train journeys (Jüttner et al., 2013). Designating seven journey touchpoints allowed for greater and less restricted depth in conversation during our semi-structured interview.

Participants ticked the appropriate emotional response that correlated with their experience of that touchpoint using this 'smiley scale', informing their affective states at each journey touchpoint. Although not a proper validated Likert-type scale, it was used for averaging and aggregating participants' perceptions about phases of train journeys. The main rationale behind the application of this smiley scale was to foster discussions and probe conversations during the interview process. Follow up questioning was tailored to and based on the participants' marking on the smiley scale. They were prompted to develop their recollections, explaining what worked well and not during their most recent travel experience, and how they would improve each particular touchpoint if they demonstrated a negative response during this event (Stein and Ramaseshan, 2016). 


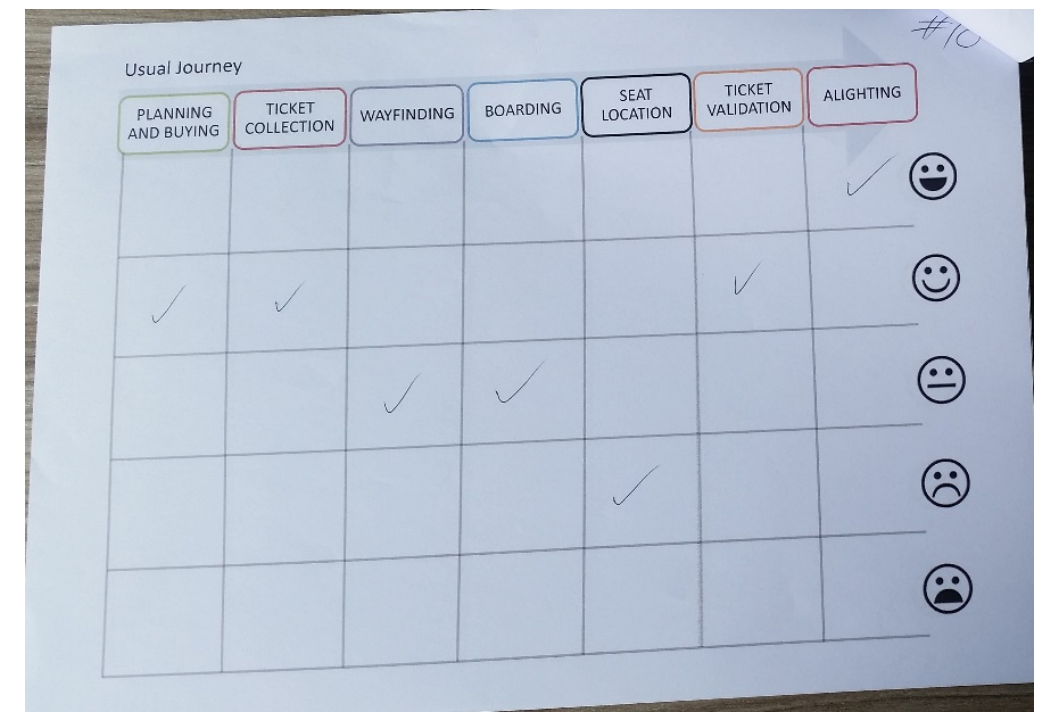

Figure 1 - Touchpoint experience rating exercise of usual journeys (baseline). An identical grid was used towards the end of the interview as a measurement of experiences considering the hypothetical implementation of the proposed technology.

Halfway through the interview, participants were presented with technologies that could be implemented with the intention to enhance rail travel. Whilst the initial probe and questioning served to establish a baseline relative to participants' responses to the present system in place, the presentation of emerging technologies was introduced halfway through specifically to measure the changing degrees of utility and affective responses triggered by these proposed innovations. A diagram (Figure 2) was used by the researcher as a guide to describe the different system features. The technology was presented as a possibility, and not features which passengers would be forced to use. 


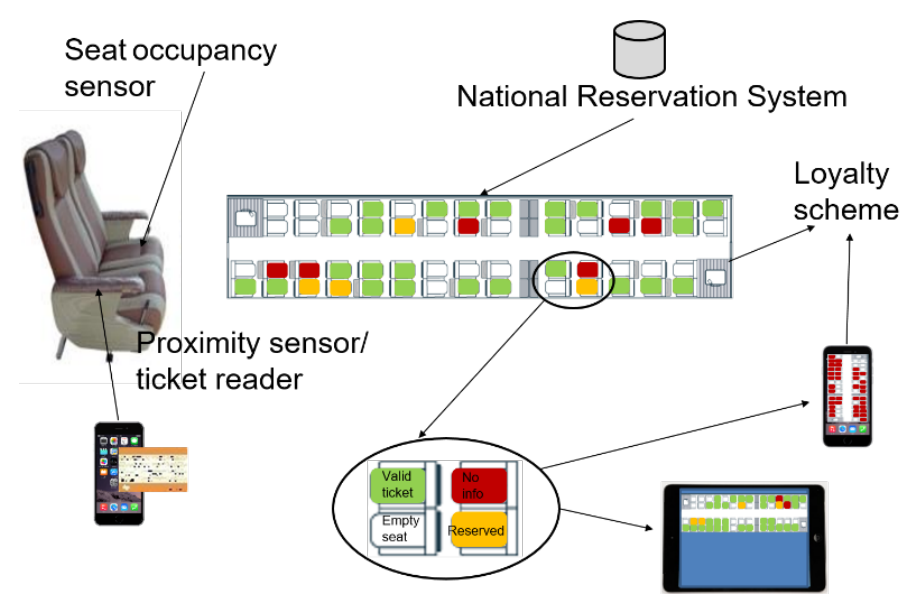

Figure 2 - Diagram of the features presented to participants (counter-clockwise): Data from the national reservation system combined with seat sensors can show train occupancy in real-time. This information can be relayed to crew interfaces, platform screens and smartphone apps. Ticket readers on armrests allow passengers

to 'check-in', therefore there is no need for crewmembers to check valid tickets. The system can display reserved, occupied and empty seats, so passengers can choose and reserve their preferred seats at any time. A loyalty scheme can aggregate these features as an umbrella online service.

The proposed features of new rail systems suggested to participants, previously listed by Oliveira et al. (2019) included:

1. A diagram of free and reserved seats on your phone or screens on the train and platform

2. Ability to search for, reserve and/or change your seat before and during your journey

3. Access to live information showing the occupancy levels of current and future trains

4. Directions displayed on your phone to help you find your platform and your seat on the train

5. Access to live journey information (e.g. ETA, alternative travel routes in the event of disruptions)

6. Ability to validate your ticket electronically at your seat, so you don't need to present your ticket for inspection

7. Information on facilities at your destination station (e.g. details of bus connections, phone number of taxis)

8. Ability to earn rewards through a loyalty scheme and redeem points for rail or nonrail purchases

9. Ability to pre-order special services (e.g. refreshments, train manager assistance)

10. Automatic compensation for late or cancelled trains

A final probe comprised paper slips with the proposed technologies, shown in Figure 3. Participants were not only asked to read through these flashcards but, as another form of probing to stimulate further questioning, they were asked to rank these proposed technologies in terms of which would improve or worsen the participants' experience. They arranged the 
flashcards in a vertical row from most to least relevant to their needs, which remained on the table during the second half of the interview to allow for easy reference back to the proposed technologies.

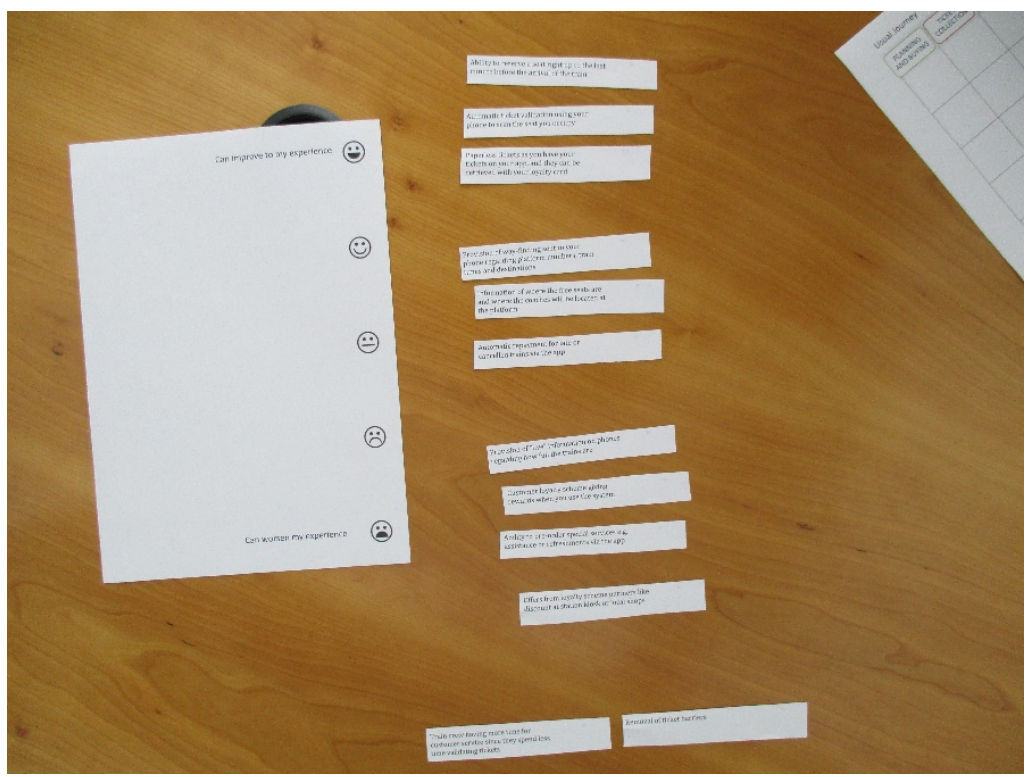

Figure 3 - Ranking exercise with which participants placed the proposed features against a smiley scale

Participants were presented with a second blank journey map table, identical in format and with touchpoints consistent with the initial map they filled out. Thus, for each participant there existed two filled-out journey maps - one serving as a baseline representing past experiences and the other serving as a hypothetical set of responses to future innovations which could be compared to demonstrate the changing degrees of each participants' levels of affect.

Table 2 - Protocol used during the face-to-face interviews

\begin{tabular}{c|l}
\hline Face-to-face interview protocol & Description of procedure and questions \\
\hline Preamble and baseline measurements & $\begin{array}{l}\text { Participant fills in demographics sheet } \\
\text { Describes typical journeys (origin and destinations) } \\
\text { Fills in the journey experience map }\end{array}$ \\
\hline $\begin{array}{l}\text { Current journeys phases } \\
\text { - Planning / reserving }\end{array}$ & $\begin{array}{l}\text { Questions and prompts for exploration (for each } \\
\text { phase): }\end{array}$ \\
- Ticket Collection & $\begin{array}{l}\text { Thinking about those recent typical } \\
\text { - Wayfinding }\end{array}$ \\
- Bourneys, how did you [e.g. plan / reserve \\
- Seat location & $\begin{array}{l}\text { your ticket?]? } \\
\text { Ticket validation }\end{array}$ \\
\hline
\end{tabular}




\begin{tabular}{|c|c|}
\hline - Alighting & \\
\hline Reveal the proposed technology & Researcher shows diagram and outline system \\
\hline $\begin{array}{l}\text { Assessment of perceptions towards the proposed } \\
\text { technology through interactive ranking exercise }\end{array}$ & $\begin{array}{l}\text { Participant places each feature on the smiley scale } \\
\text { and explains the motivation for each choice }\end{array}$ \\
\hline $\begin{array}{l}\text { Assessment of possible changes in perceptions } \\
\text { motivated by the proposed technology }\end{array}$ & $\begin{array}{l}\text { Repeat journey map and interview in relation to } \\
\text { proposed benefits }\end{array}$ \\
\hline $\begin{array}{l}\text { Postscript evaluation of the impact of the technology } \\
\text { on hypothetical future journeys: } \\
\text { - Planning / reserving } \\
\text { - Ticket Collection } \\
\text { - } \text { Wayfinding } \\
\text { - } \text { Soarding } \\
\text { - Ticket validation } \\
\text { - } \text { Alighting } \\
\end{array}$ & $\begin{array}{l}\text { Questions and prompts for exploration: } \\
\text { - How would the process of [planning / } \\
\text { reserving your ticket] change with this } \\
\text { system? } \\
\text { - What would you use? } \\
\text { - What would work well and what wouldn't? } \\
\text { - How would you make improvements? }\end{array}$ \\
\hline
\end{tabular}

\section{Questionnaires}

Further data was gained from 50 questionnaires given out to rail users in the field. In terms of both convenience sampling and eliciting the most detailed amount of information from questionnaire respondents possible, passengers on board weekday, off-peak trains between London and South West England were approached. The working assumption behind this rationale was that off-peak travellers would be the most receptive to filling out a questionnaire in detail, likely having more time and space, whilst the carriage environments would be optimal and not overcrowded to allow the researcher ease of access. Passengers were randomly approached to fill in questionnaires and a consent form. Carried out whilst on board trains, responses from participants collected in the field were valued because passengers were being asked to reflect on an experience they were currently experiencing. Additionally, it also imbedded a felt sense of systemic interrelation into the methodology since passengers were asked to fill out questionnaires whilst surrounded by other passengers being asked to fill out questionnaires. One of the authors would then collect the questionnaires a few minutes later.

The questions for these participants paralleled the contents of the face-to-face interviews; whilst interviews revealed largely varying degrees of responses, the follow-up use 
of questionnaires was intended to better understand the average experience of travellers, and

so the most commonplace and least stressful context for travelling was selected. Proposed

technologies were listed discretely as individual items, and questions were posed for

respondents to freely write their answers on the paper. Table 3 presents the content of the

questionnaire, which was formatted to contain boxes for each response. A pen was also

provided if required by participants.

Table 3 - Questionnaire given to passengers on board trains. These were printed on A4 sheets with spaces for responses.

\begin{tabular}{|c|c|}
\hline Onboard questionnaire & Questions \\
\hline $\begin{array}{l}\text { Preamble and baseline } \\
\text { measurements }\end{array}$ & $\begin{array}{l}\text { Participant fills in demographics sheet } \\
\text { Describes typical journeys (origin and destinations) } \\
\text { Fills in the journey experience map }\end{array}$ \\
\hline $\begin{array}{l}\text { Planning and reserving seats } \\
\text { Ticket collection }\end{array}$ & $\begin{array}{l}\text { How did you plan your travel today and purchase your tickets? } \\
\text { - I organised in advance, bought my ticket online before today } \\
\text { - I planned my journey and bought my ticket both today at the station } \\
\text { I possess a season pass } \\
\text { Additional details: Were there any difficulties? How could it be improved? } \\
\text { Did you reserve a seat? } \\
\text { - Yes } \\
\text { - No }\end{array}$ \\
\hline $\begin{array}{l}\text { Wayfinding } \\
\text { Boarding } \\
\text { Seat location }\end{array}$ & $\begin{array}{l}\text { What was your experience of boarding and locating a seat? } \\
\text { - I was able to smoothly board and locate a seat efficiently } \\
\text { There was an issue regarding boarding or finding a seat } \\
\text { Why do you think this was? Could an improvement be made? }\end{array}$ \\
\hline $\begin{array}{l}\text { Disclosure of the proposed } \\
\text { technology and open-ended } \\
\text { questions }\end{array}$ & $\begin{array}{l}\text { Consider the introduction of the following technologies on the trains you } \\
\text { take: } \\
\text { Technology fitted into train seating that senses whether it is empty or } \\
\text { occupied. From this, the busyness of the overall carriages and the location of } \\
\text { particular free seats can be relayed to mobile apps and platform screens in } \\
\text { 'real-time' before the arrival of a train. } \\
\text { - How would your personal journey experience be affected - } \\
\text { positively or negatively? Why? } \\
\text { The possibility of reserving a seat via a mobile app and doing so 'last-minute' } \\
\text { just before the arrival of a train, in relation to which carriages and seats are } \\
\text { least busy. Displays above the seats will change to 'Reserved' in real-time. } \\
\text { - How would your personal journey experience be affected - } \\
\text { positively or negatively? Why? } \\
\text { You will be able to 'check-in' at your chosen seat, signalling that a valid } \\
\text { ticket holder has boarded and has filled their specific seat. The train manager } \\
\text { will not need to validate your ticket mid-journey. } \\
\text { - How would your personal journey experience be affected - } \\
\text { positively or negatively? Why? }\end{array}$ \\
\hline
\end{tabular}




\section{Analysis}

The audio recordings from interviews and the responses from the questionnaires were aggregated and transcribed together into a software for qualitative data analysis (QSR International NVivo), which allowed for collective coding. The transcriptions allowed a process of thematic analysis (Braun and Clarke, 2006), which was performed primarily by one of the authors and cross-checked by another researcher. Relevant statements were tagged into specific codes and clustered into themes indicating their frequency and importance.

Beginning with an initial attempt to make sense of the data, the responses for each journey touchpoint from each participant was plotted onto aggregated maps (Figure 4 and Figure 5) to provide average scores of affect. To make this aggregated journey map a better representation of the averaged affects, we incorporated an interpretation of what people actually said and how they described each touchpoint, and displayed the data in correlation with emotional faces they corresponded to.

The following task was to outline the variables that represented our participants' responses, through a process of highlighting themes relevant to rail travel and technology, surrounding the proposed technologies. We then ranked each respondent in terms of the expressed variables, according to their position on a scale from most-least association to that variable; a method previously outlined by practitioners (Cooper, 1999; Goodwin, 2009). These variables are non-binary attributes, they reflect a continuum from a negative to a positive user perception (Burrows et al., 2015). With all data plotted, patterns were seen where individuals expressed the same shared interests across different ranges of the variables, honing in on specific variables that were most common amongst participants, leading to the indication of four personas based on this refining and reducing of the variable responses (Burrows et al., 2015; Haines and Mitchell, 2014). 


\section{Mapping personas}

One method used during the analysis of the results was to hypothetically map out customer journey maps as if completed by our four personas, drawing them back onto the original journey maps and adding their probable affect as recorded for each touchpoint. Quotes and paraphrases from interviews and questionnaires were included in the journey maps to improve the tangibility and relation to the initial data of our personas. These quotes, illustrated by speech bubbles on the journey maps, were assigned to the personas to explain their reasons for the given affect at each event. This way, each persona was justifying their choices in exactly the same way that initial interviewees were prompted and guided to speak, probing the kinds of affective responses felt, then questioning and hypothesising the reasons behind this. This process revealed stark similarities between personas mapped reflectively onto journey maps, and the responses averaged from the initial data.

\section{Workshopping personas}

One way in which to grasp the systemic relevance of an interdependent sociotechnical network through the use of personas is to workshop these personas, a process that enabled greater clarity and exploration of the possible relations and interdependence between users' levels of utility. Informed by the popularity of systemic thinking in forms of psychotherapy, the personas were subjected to a kind of group, speculative counselling session (Kerr, 1981), in which their preferences and feelings regarding other users (represented by the other present personas) were played out and imagined as part of a single interdependent network.

More generally, we take 'workshopping' not as the informal academic gathering and the casual talking about data (Blommaert, 2004), but more as the concept from drama and literature of creating and revising a piece of work before public appearance. We took our personas as characters out of static fiction, opening up the fixed sense of tableaux to the 
hypothesising of narratives and relational stories, so that discrete personas became continuous within a theorised space and time. This is a mobilisation of personas, and the more they are prompted to embody not just stereotypes (Turner and Turner, 2011) but also narrative archetypes and journeys of their own, the more likely they are to take over from research; they become their own guiding forces and give sense to their own goals and relations in and by the interconnected system they are workshopped in and through. Grudin (2006) comments on the process of acting and its similarity to the creation of personas, presenting further support for the idea that a mobilisation of personas can be achieved through workshopping. The more mobile we are with the personas, the more likely they are to interact and become fluid, relatable and allow designers, systems engineers and developers to visualize how discrete users could interact within a shared system.

Workshopping the personas creates a circular workflow encompassing the qualitative data analysis, customer journey maps and personas creation, mapping these personas, giving voice to each persona, narrating the interdependencies between personas within the map touchpoints, then illustrating and verifying these narratives with initial data and quotes (Figure 4). This circularity of method assisted the validation of the personas and fostered further understanding of the systemic relationships between users - not merely all possible real users, but relations between different affective responses and utilities, whether these are provoked in the empirical data, the fictionalised narratives, grounded in the individual's consciousness, sustained in and by the social sphere, or produced by technological advancements. The method itself was part of engendering a circular way of thinking - a mode of understanding how best to balance the needs and utilities of - bringing together an intersubjective understanding of all research subjects and objects as engaged in feedback loops with each other, informing a systemic and interrelated understanding of the public and rail transport. Overall, as shown in Figure 4, this forced a more rounded consideration 
towards the original data, customer journey maps, created personas and the final threading of each persona back into the original data, onto journey maps, and into relation with one another.

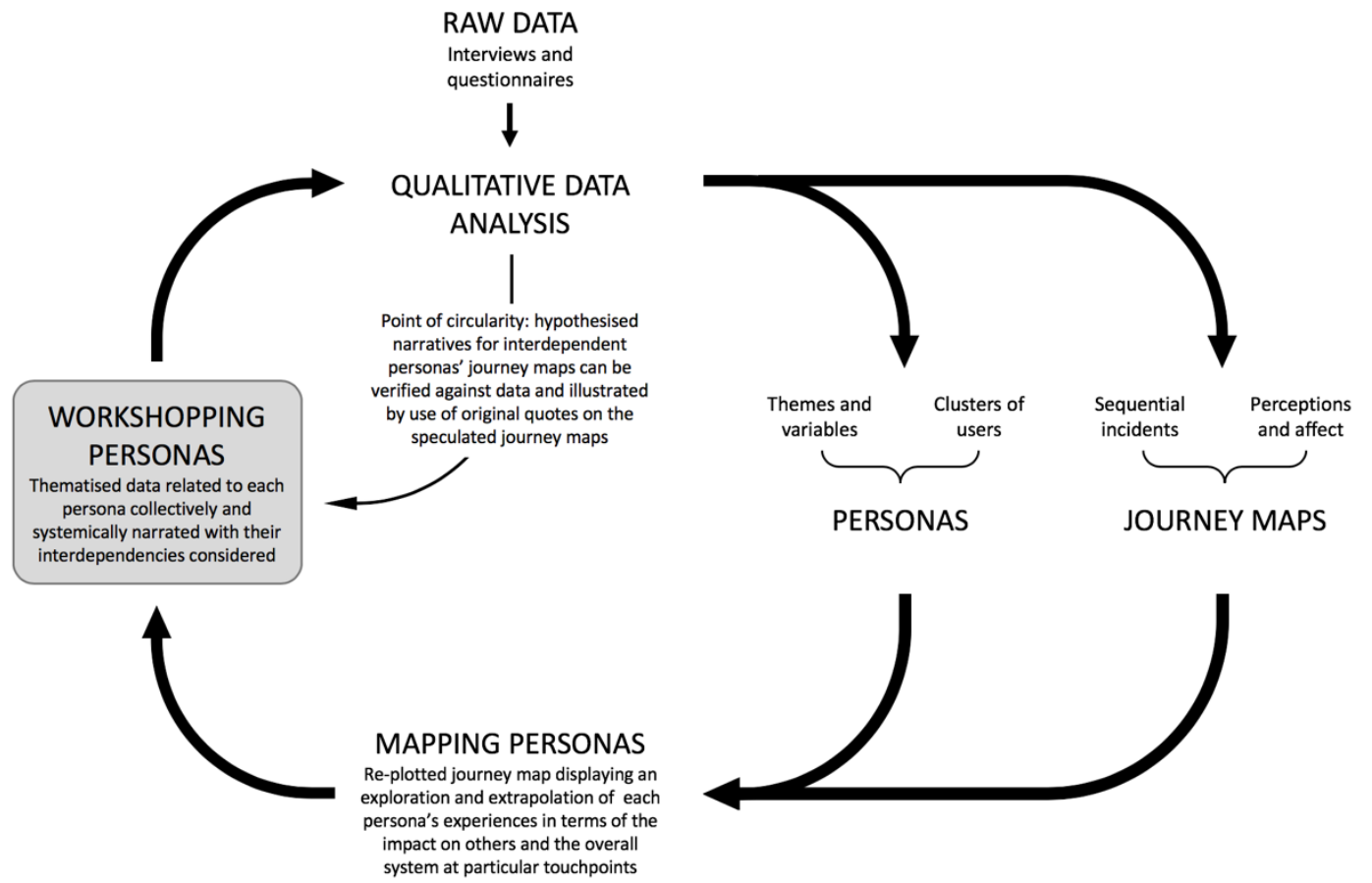

Figure 4 - A visualisation of the systemic UX process of collectively mapping and workshopping personas combining individual journey maps and personas

\section{Results}

\section{Qualitative data analysis}

The thematic data analysis performed during this research indicated that participants have generally strong negative and positive opinions regarding a range of issues related to train travel. Table 4 summarises our dataset and the ways in which we coded responses according to specific thematic areas, representative of the particular aspects of utility. We observed participants' relationship with the railways in terms of the touchpoints with the system and eventual painpoints. The first column contains the thematic areas, the middle column shows the number of participants whose interview or questionnaire transcripts 
contained statements within that theme, and the last column shows the number of mentions extracted from the dataset. Often participants mentioned issues coded in more than one node, hence the sum of participants from each row within a theme will provide a larger number than the theme headings. Quotes from participants are presented below to illustrate the qualitative data analysis, and the resulting four personas are presented in the next section.

The information in Table 4 indicates positive comments about the current rail system, for example regarding planning journeys, buying and collecting tickets. Passengers mentioned the advantage of using online services to find cheaper tickets and/or select their preferred type of reserved seats. However, nine respondents declared they appreciate buying tickets at the station, for the convenience or to talk to staff and obtain a cheaper fare. Wayfinding at stations and boarding trains result in positive experiences for twelve travellers. The process of onboard ticket validation, when the train manager checks who has the right to travel, was positive for fourteen participants. They appreciate having a figure of authority on board, someone to resolve conflicts, or simply someone to interact with. Participant 9 [P9] illustrates this point saying that "I don't mind someone coming round and checking. It's nice to have an actual person, and you can ask them about the station you're going to".

We observed a large number of negative comments about the current rail travels, for example concerning the process of planning, buying and collecting tickets. There were complaints about the difficulty to find cheap tickets online, the queues to print tickets at the station machines, and the time and effort involved. A number of issues were also highlighted about reservations and seat location. Mentions were more frequent related to crowdedness, unreliability, and the fact that people often do not take their reserved seats. P7 spoke about " $a$ chain of three of four people where somebody is in a reserved seat because they've been kept from their own reserved seat". 
After the researcher presented the ten technological features that could be implemented into the railways, participants mentioned a number of aspects that could improve travel experiences. These include planning journeys, buying and collecting tickets, for example the convenience and environmental benefits of not relying on paper tickets. Passengers appreciated the features to improve wayfinding, such as the personalised directions to the correct train coach. P19 illustrates with their personal circumstances: "[B]ecause of my bike, sometimes I don't know where the bike carriage is, and that would be really useful'. Other benefits include reservations and seat location (such as the features providing real-time indication of seat occupancy) and ticket validation (efficient process, less disturbance and the possibility of eliminating the ticket barrier at stations). Passengers also discoursed on other issues not directly prompted by the customer journey map, and a few topics emerged from these discussions, which indicated new themes. These comprise crew interaction (the possibility of arranging special services and customer care), a rail loyalty scheme (rewards for frequent travellers with automatic compensation for delays or cancellations), and the benefits of added software and technology into the railways (making better use of smartphones for real-time digital services).

Despite the potential benefits provided by the proposed system, a large number of issues emphasised by passengers represented negative comments towards the technology. For example, as the system focus on buying tickets and reserving seats up to the last minute, three participants were quick to notice that these tickets will likely be more expensive, since discount prices are only found if you buy in advance. When analysing the wayfinding features, two passengers suggested that informing where the free seats are will be of no benefit if the system is used widely. P17 exemplifies:

The only thing you'd have is, if loads of people bought a ticket and then they can see one carriage has got tonnes of seats, everyone's going to go for that one carriage. Whereas now, 
if it's busy, anybody gets on the shortest queue and then walks through the train. I don't know if it would make boarding easier.

When thinking about the proposed process of reserving and locating a seat in realtime, passengers indicated that there is potential for exacerbating conflicts, especially considering that the system will not solve overcrowding. P6 illustrates this issue, adding to the fact that the validation process may reduce the presence of onboard crew:

Some of the current problems, it won't improve. Like a conflict seat, people will still sit in seats and insist it's theirs. And because there's no staff around, unless you want to physically drag the man out, you won't get your seat.

Sixteen participants emphasised potential problems with the proposed system if it disregards or disadvantages the elderly, poor or other often marginalised groups of people. Sometimes they were talking about themselves ("I have a Windows phone so they'll probably never make an app for my phone" [P4]), but often thinking about someone else [P12]:

I suppose potentially it could be discriminatory. People will get a preferential treatment, it would marginalise some people... particularly those with special needs, the elder for example, not everybody has a phone that can have apps.

Participants appreciate crew interaction and saw with concerns the risk of not having the physical presence of a train manager on board checking tickets. The possibility of having a loyalty scheme for rail travel was seen negatively by sixteen participants, often due to the displeasure with similar services. The theme labelled as software, involving the system itself and the need for smartphone apps, encompass concerns about the reliance on technology which often fails, and doubts that the system can actually improve their travels.

From our data emerged issues with acceptance and familiarity of technology, of crucial importance for a project proposing new features for the railways. Namely, electronic ticketing, dynamic seat reservation, wayfinding information and loyalty scheme seemed to be the contentious points among our sample, and therefore were chosen as the main variables to 
classify participants. The subsequent results sections present the impact of proposed

technology on our personas, especially when they are overlaid on the customer journey maps to illustrate their travel experiences.

Table 4 - Summary of the qualitative data analysis showing the positive, neutral and negative mentions by our participants as collected from interviews $(n=20)$ and open-ended questionnaires $(n=50)$. Data is separated by mentions concerning the current journeys and hypothetical journeys with the proposed technology.

\begin{tabular}{|c|c|c|}
\hline Thematic areas & Participants & Mentions \\
\hline Specific to current journeys & 46 & 361 \\
\hline Positive & 32 & 90 \\
\hline Planning-Buying-Collecting & 17 & 39 \\
\hline Wayfinding-Boarding & 12 & 12 \\
\hline Reserving-Locating Seating & 1 & 1 \\
\hline Validation & 15 & 32 \\
\hline Misc. & 5 & 6 \\
\hline Neutral & 27 & 58 \\
\hline Planning-Buying-Collecting & 26 & 37 \\
\hline Wayfinding-Boarding & 9 & 13 \\
\hline Reserving-Locating Seating & 6 & 7 \\
\hline Validation & 1 & 1 \\
\hline Negative & 32 & 212 \\
\hline Planning-Buying-Collecting & 20 & 35 \\
\hline Wayfinding-Boarding & 20 & 76 \\
\hline Reserving-Locating Seating & 24 & 63 \\
\hline Validation-Barriers & 17 & 21 \\
\hline Misc. & 9 & 17 \\
\hline With the proposed technology & 68 & 473 \\
\hline Positive & 63 & 185 \\
\hline Planning-Buying-Collecting & 11 & 13 \\
\hline Wayfinding-Boarding & 19 & 26 \\
\hline Reserving-Locating Seat & 33 & 47 \\
\hline Validation-Barriers & 13 & 16 \\
\hline Crew interaction & 3 & 3 \\
\hline Loyalty scheme & 36 & 47 \\
\hline Software and app & 7 & 8 \\
\hline Misc. & 21 & 25 \\
\hline Neutral & 34 & 80 \\
\hline Planning-Buying-Collecting & 1 & 1 \\
\hline Wayfinding-Boarding & 3 & 4 \\
\hline Reserving-Locating Seat & 8 & 8 \\
\hline Validation-Barriers & 19 & 32 \\
\hline Crew interaction & 8 & 10 \\
\hline Loyalty scheme & 18 & 19 \\
\hline Software and app & 2 & 2 \\
\hline
\end{tabular}




\begin{tabular}{l|r|r} 
Misc. & 4 & 4 \\
\hline Negative & $\mathbf{5 1}$ & $\mathbf{2 0 8}$ \\
\hline Planning-Buying-Collecting & 6 & 7 \\
Wayfinding-Boarding & 8 & 10 \\
Reserving-Locating Seat & 19 & 23 \\
Validation-barriers & 14 & 16 \\
People excluded or disadvantaged & 16 & 27 \\
Crew interaction & 14 & 22 \\
Loyalty scheme & 16 & 19 \\
Software & 25 & 57 \\
Misc. & 18 & 27 \\
\hline
\end{tabular}

\section{Personas}

The qualitative and quantitative responses obtained from questions during the interviews were combined with the data from questionnaires to provide a more holistic understanding of passengers' characteristics, opinions and feelings. We refined the set of variable responses down to four thematised aspects of utility that corresponded to the proposed technological innovations. These comprise openness to electronic ticketing, dynamic seat reservation, enhanced wayfinding assistance and a loyalty scheme - which were condensed into the personas. In other words, data across the interviews and questionnaires indicated clusters of behaviours, needs, motivations, characteristics and limitations, which were compiled into four empirically derived personas: Tina (Figure 5), Lin (Figure 6), Harry (Figure 7) and Joseph (Figure 8) below, briefly described previously in Oliveira et al. (2018). We present below how these personas interact with the current rail system at specific touchpoints of a journey map, and how they would feel if the proposed technologies were implemented. 


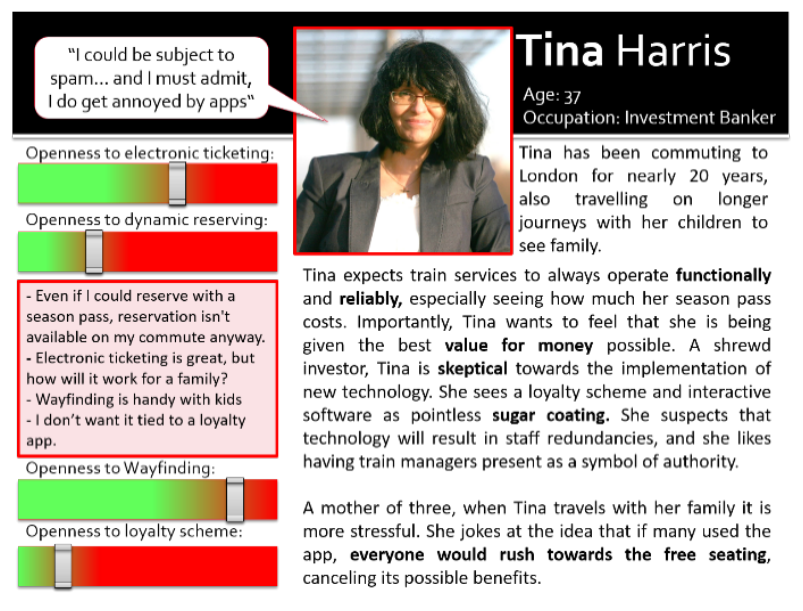

Figure 5 - Persona card: Tina

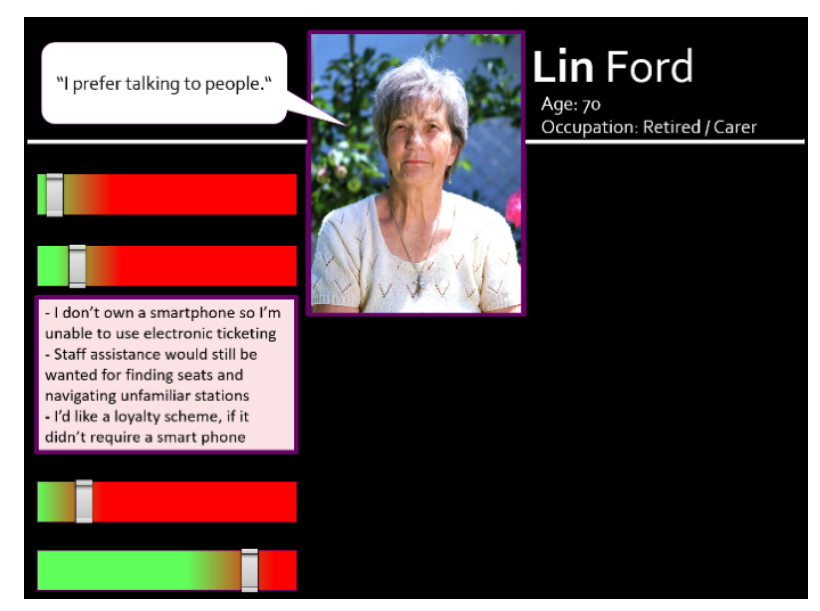

Figure 6 - Persona card: Lin

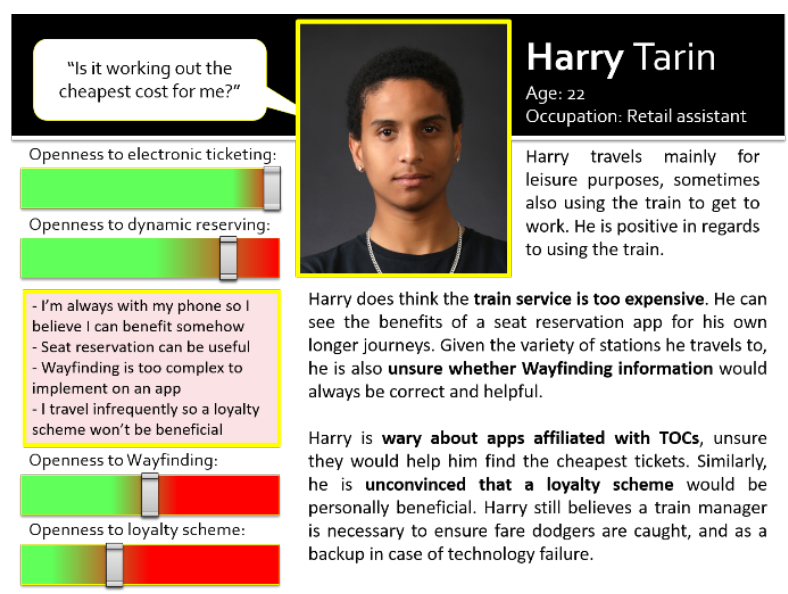

Figure 7 - Persona card: Harry 


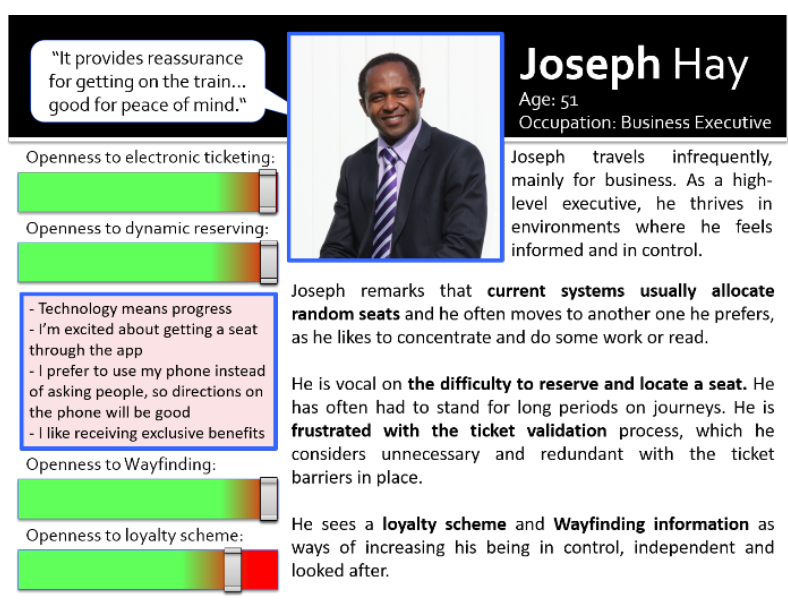

Figure 8 - Persona card: Joseph

The process of 'planning journeys and buying tickets' is usually positive for passengers. That is because there are diverse alternatives to suit individual preferences. Some, like Joseph, do it on the web via their preferred vendor, some using their favourite apps on smartphones, and some still prefer to buy at the station from the ticket office. However, passengers showed resistance to using other methods. Harry particularly notes his preference for online split ticketing and using multiple vendors. Most of the concerns from users such as Lin are that she prefers the assistance of a staff member.

In the process of 'ticket collection', Lin does not use ticket machines, will not use electronic ticketing, and expects not to be forced to do it. However, she has no qualms with it being available to other passengers. Joseph would adopt electronic tickets straight away if it was convenient and gave him control, and so would Harry, as long as it gave him the cheapest ticket.

The process of 'Wayfinding' (i.e. navigating the station up to the platform and train) provoked the second most negative affect responses from passengers. Being unclear on directions or your journey route is a problem that affects people diversely. Tina and Lin acknowledge they have to learn routes by repetition or simply ask for assistance. Joseph and Harry would embrace wayfinding information if relevant and trustworthy. 
The process of 'boarding' is another aspect of people's journeys that prompts many negative responses. There is often the worry of 'is this the right train?' Lin voiced concerns for safety and reduced ability to board and cope in physically demanding situations. Boarding seems to provoke a 'keep calm and carry on' nature in the face of stress for many passengers, especially commuters and business archetypes like Tina and Joseph. There is potential for technological improvements during the boarding process, although Tina knows that it will not be of much help when trains are crowded.

The process of 'Seat Location' is one of the most unpleasant during train journeys. This happens generally because people want seats, and they sometimes are not available. Almost all users feel they have an especial claim to a seat. Whether it be Joseph needing room to work, Tina needing space for her children, Lin who is unable to stand for long periods, and Harry who says that since tickets are expensive, seats must be available.

The 'ticket validation' provoked some of the most diverse responses, with Lin enjoying the human contact, Tina enjoying the assured safety from an onboard authority, Harry wanting to make sure other travellers are also paying, and Joseph wishing to be left alone.

Generally positive responses at the point of 'Alighting' is indicative of user's improved overall experiences as a result of arriving at their destinations. Remaining issues were Lin's need for assistance and Joseph's concern for finding his next train.

\section{Average experiences}

Interviewees rated their travels in relation to seven common touchpoints with the rail system on a 5-point smiley scale, and the results can be seen below. Figure 9 presents the average mapping of users' affective responses elicited by the present system during their most recent journey. Figure 10 shows participants' changing responses if emerging technologies were implemented during their journeys. There is a noticeable increase in the 
average rating for all touchpoints once new technologies are introduced, especially for the processes of ticket collection, wayfinding, and boarding and seat location.

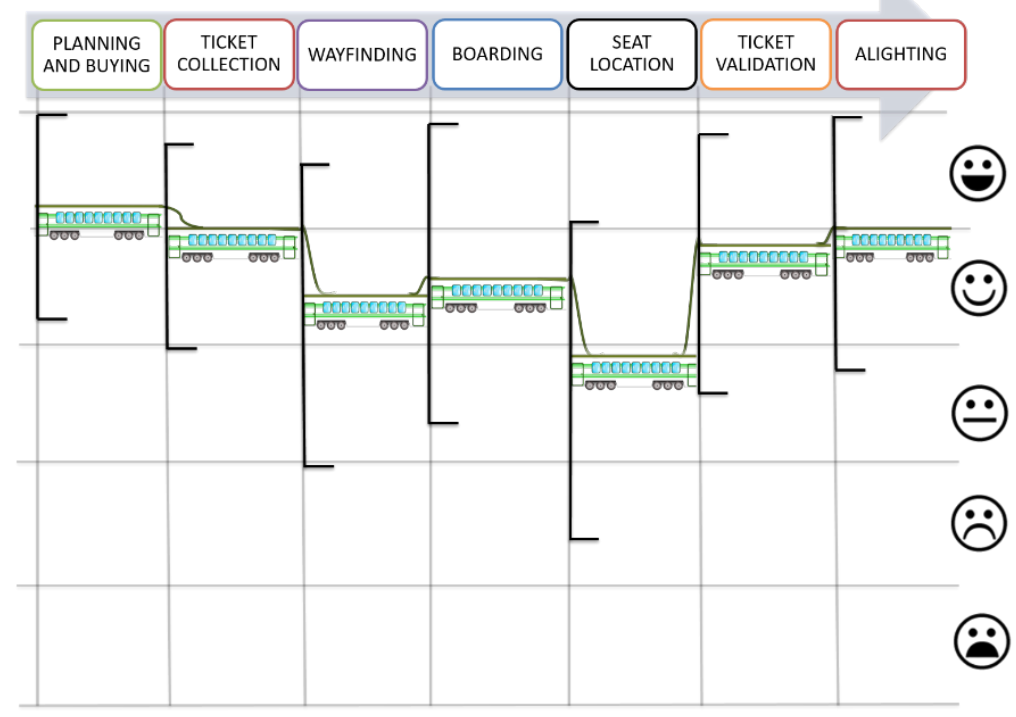

Figure 9 - Journey mapping of current journeys, with mean affect (represented by the train coaches following the black line) and deviations (represented by the vertical lines prior to each train coach illustration)

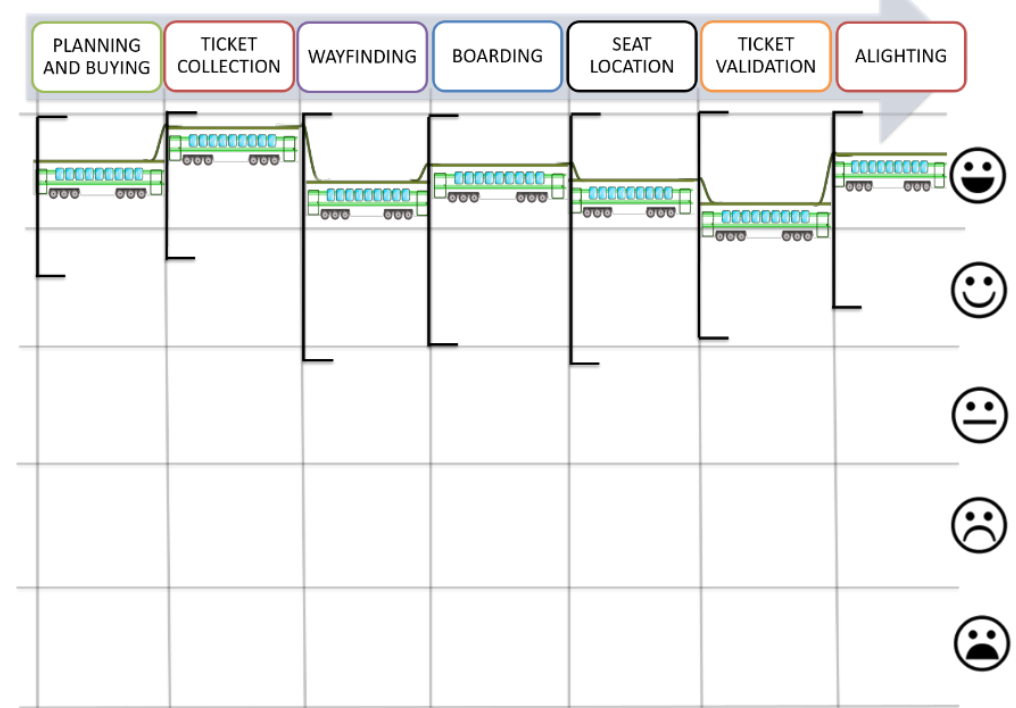

Figure 10 - Journey mapping of hypothetical journeys with the proposed innovations, showing mean affect (represented by the train coaches following the black line) and deviations (represented by the vertical lines prior to each train coach illustration) 


\section{Workshopped personas}

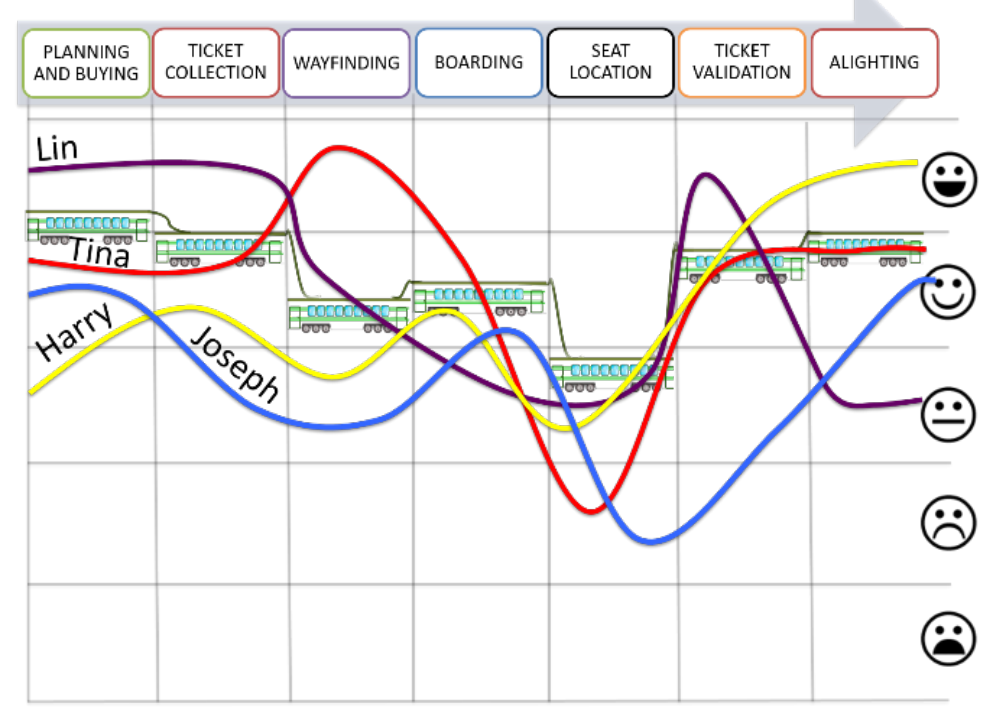

Figure 11 - Persona's experiences of current journeys with mean affect (represented by the train coaches following the black line) and each persona's hypothesised user experience (represented by the coloured lines)

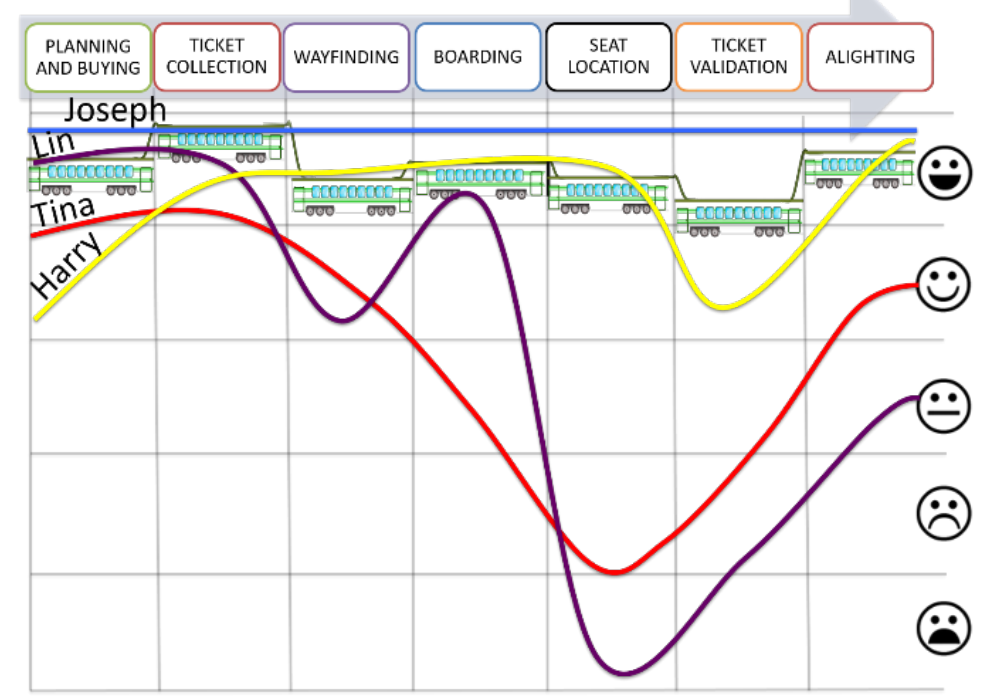

Figure 12 - Persona's experiences of hypothetical journeys with proposed technologies, with mean affect (represented by the train coaches following the black line) and each persona's hypothesised user experience (represented by the coloured lines)

Figure 11 shows our personas' journey map with lines representing their experiences.

If the proposed technologies were implemented, the experiences for the same passengers would be as pictured in Figure 12. There is an overall affect improvement for some 
passengers, for example Joseph, in which straight line on the top of the graph next to 'very happy' indicates that the business professional would benefit from the technology in all stages of the journey. Harry would also appreciate the new system features for most of the time. However, it is clear that for other passengers and at some stages, the journey experience worsened remarkably. That is the case for Lin and Tina during seat location and ticket validation. The deterioration of their experiences is made more remarkable if we compare it with the average experiences, shown by the image of train coaches following the black line.

Figure 13 and Figure 14, below, highlight the two most divergent persona responses from the aggregated, averaged data collected from all journey maps filled out by interview participants. Worth noting the discrepancy between the original mean affects and those expressed Lin and Tina, especially at the 'seat location' and 'ticket validation' touchpoint. As a means of better understanding these divergent affective responses equally and without discrimination - without merely identifying them as anomalies outliers - quotes are given from original interviews to generate understanding and acceptance of these more diverse needs and desires that do not readily correlate with an aggregation of averaged utility.

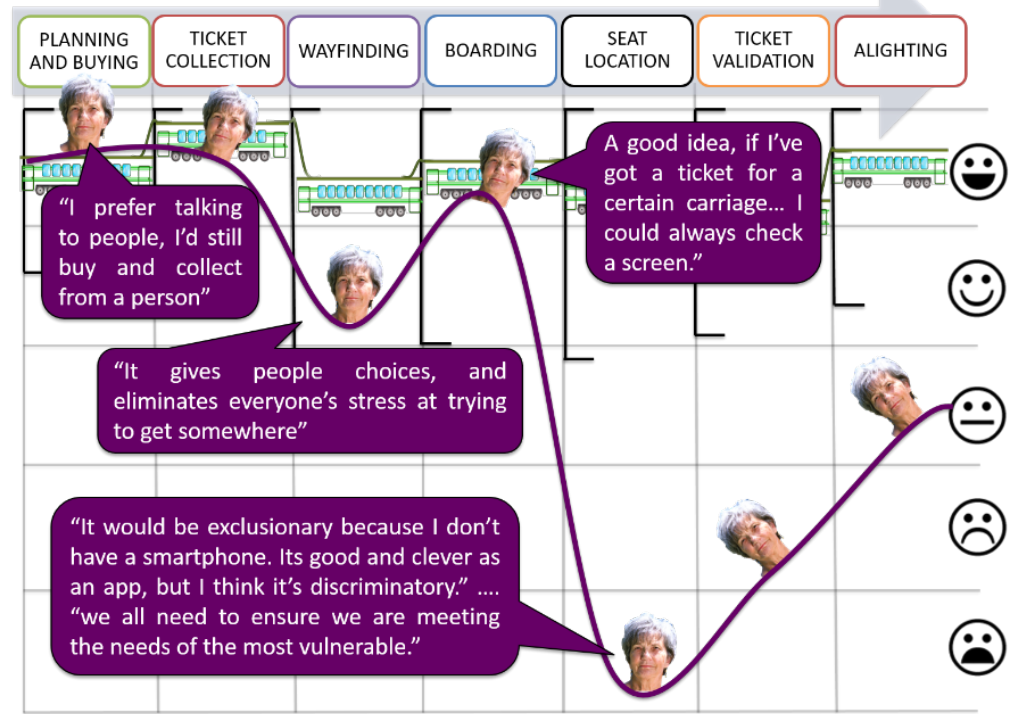

Figure 13 - Lin's experiences after the hypothetical technology being implemented 


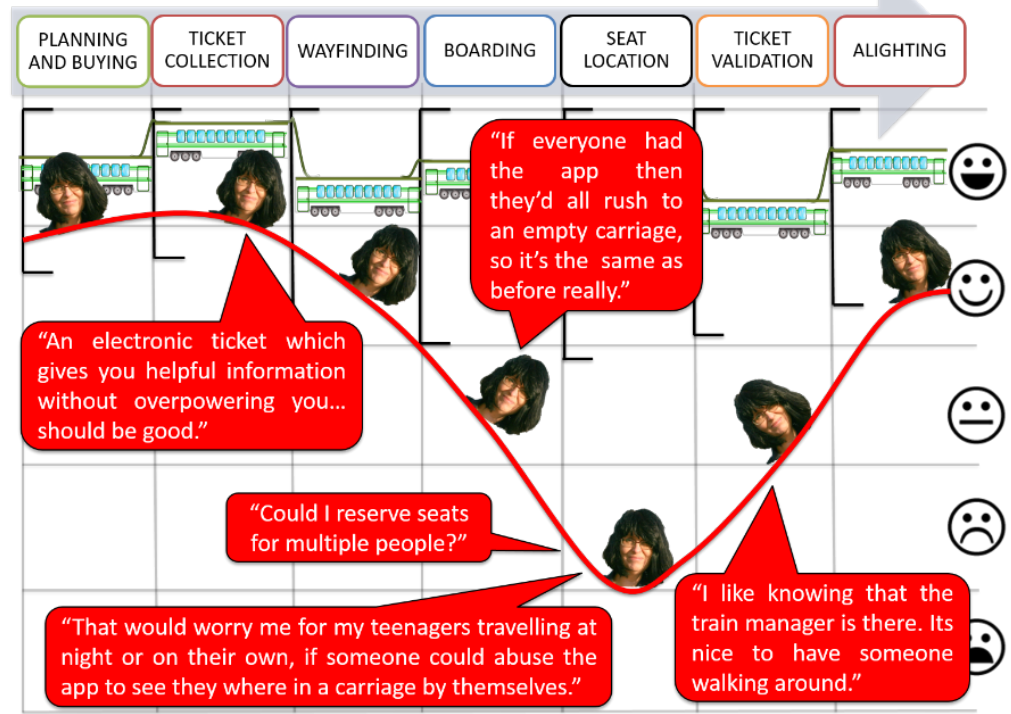

Figure 14 - Tina's experiences after the hypothetical technology being implemented

\section{Discussion}

This section expands upon the rationale behind the project's aims, methods and findings, assessing in what ways and the degree to which this reasoning was successfully implemented during our research. By reference to the previously included Table 4 as well as journey maps and personas, this discussion tends toward trying to work through the realisation of a systemic, interconnected socio-technical network in the data and their presentation. User personas and customer journey maps were decided upon as an efficient platform that served as a basis where philosophical principles surrounding a more systemic UX were tested. This was for two reasons: (i) personas are at once empirical and yet open up a space for subjective engagement with data, involving researchers in creative approaches to method and presentation, and (ii) customer journey maps provided the stage for acting the personas and highlighting their interdependencies at specific points in time and space, crucial for the workshopping activities performed.

Cooper states that "personas are defined by their goals" and that "identifying a primary persona is a vital step in development" $(1999$, p. 124). His idea centres on the notion that if we design for the most demanding persona, others who have fewer specific needs will 
also be satisfied in the process. This practice is theorised in Cooper's examples of the necessity to 'design for just one person'. There is a major issue in this and the industry's attention to the individual, however. The dynamism of people's possible pleasures is a factor to consider. Moreover, designing for individuals seems disjunctive with the evident concept that trains are systems compiled of many interconnected users with unique needs. Furthermore, these users are sharing a collective scenario where interactions take place, as highlighted by our data and the interconnectedness of personas. Despite attempts to induce participants only to speak of themselves, as is customary in user research, it was rare for anybody not to bring up the actions, wants or needs of other passengers.

Customer journey maps are likewise frequently designed to represent a typical user or one main actor (Oliveira et al., 2017; L. C. Oliveira et al., 2020), and although they may "combine various perspectives in one map" (Stickdorn and Schneider, 2010, p. 46), those are often plotted as a means of contrasting experiences of diverse groups of people, for example clients and employees. When laying all personas over our journey maps, resourcing to their social needs, and populating their dialogues with qualitative data, we simulated the dynamic environment wherein the diversity of travelling public cohabit. This appeared to be a more comprehensive and representative approach to describe the socio-technical phenomena of study.

Our results show that the majority of individuals are given pleasure from a new technological system, but a few are unable to adapt, thus there is a risk that their wellbeing is compromised, and that the overall system suffers in terms of operability and functionality. This is a similar issue to those raised, and apparently fixed, by propositional utilitarianism. Such proponents unpack an example like, 'Joseph the business professional is pleased that he has a seat and the new system is ensuring overall better functionality for him and his fellow passengers' - demonstrating that self-pleasure is in fact always presupposed by the necessity 
of a certain state of interpersonal affairs. In other words, the sociological system that an individual is within must serve to facilitate the fulfilment of individual goals. And if Joseph's pleasure is to be maximised, he must not only be given a seat, but the train must also be assured to run smoothly and functionally with all its passengers. To assure this, though he may not recognize the problem, all other individuals in the system must be satisfied to the extent that they are not problematising or subtracting from the overall systemic goals. So, there is a return to the potential problem that if some are left undersigned for, the overall system could become less smooth and efficient.

Most participants in the research revealed an interest in procuring a seat through a dynamic seat reservation system as well as wanting direct personal information, similarly to previous research describing seat preferences (Wardman and Murphy, 2015). This discrete data points toward focusing UX design on individual wants for maximal pleasure. However, when users were considering themselves as a collective system, opinions changed a little, as shown in Table 4. There was a concern that the new technological means of reserving a seat would discriminate against non-technology users. Participants who would benefit from features like electronic tickets, last-minute seat reservation and automatic ticket validation showed empathy towards passengers that would be excluded or struggle to use the system. Furthermore, 33 participants at first showed excitement for their ability to locate the empty coaches and get a seat there, but a few ended with more cynicism after the consideration that every other user could potentially also be using this same technology and targeting the same seat. If all passengers were using the system, all would head to the same empty seat, neutralising the benefits.

Our results demonstrate issues surrounding the removal of human ticket validation in favour of a computer interaction. The following descriptive discussion attends to a practical and impactful expression of our findings, grounded in the data illustrated in Table 4, whilst 
the semantics and logic is informed by utilitarian consequentialism: (i) Thirteen respondents had a relative +1 preference for removing human validation whereas fourteen had a relative 3 dislike of not having the security, authority and additional help provided by the presence of crew during the validation process. The resulting displeasure would be beyond the 'zone of tolerance' (Zeithaml et al., 1993) and deemed inadequate by these users. As a result, initial aims of the proposed technology focused on removing the manual ticket validation process would result in overall displeasure from the new technological innovation. A revision of the design or deployment of this feature may be beneficial here, and of significance is the reasoning to suggest this. Not only does it heighten the ethical responsibility of a business to work to reduce displeasure (in this instance being voiced by many vulnerable individuals including the elderly and those feeling unsafe to travel alone), but so that the overall functionality and operations of rail transport would not be damaged.

Lastly, although the majority could have benefited from the technological changes, thought has to be given to the possible effects the few unable users would have on the many. If some cannot adjust to a new system, for example our personas Lin for not owning a smartphone or Tina the basic user, there stands a chance that the whole system will be slowed down. Most consumer behaviours are voluntary (Venkatesh et al., 2012), and if certain technology is presented to all customers but a share of them oppose the adoption, there is the risk of compromising the optimal functioning of the whole system. The passenger without the app or unable to use it may make other technology-able passengers uncomfortable. They can also cause more seating disruptions or may require assistance and compromises from people. Ultimately, though designing for individuals' interests is immediately sensible to satisfy the majority, these examples should demonstrate that a different mode of thinking is required. Here, user personas and experiential research could benefit from further influence from contemporary revisions of philosophical consequentialism (Feldman, 1997). 


\section{Proposing a systemic approach - Calculating systemic pleasure}

To better ensure the success of systems designs, consequentialist UX frameworks should shift away from traditional utilitarianism that emphasizes pure hedonism, individualisation and net utility. Instead, a more systemic consideration is needed towards the intricate interconnectedness between people and systems within any network. No longer measuring net utility, instead calculation should be centred on achieving (an albeit lower) gross utility that works to minimise displeasure for anyone as much as possible. This reasoning, hypothesised and tested through personas, is informed by the revisions of contemporary utilitarian philosophies as well as the wider propagation of socio-ethical paradigms surrounding equity and equality in research. For the functionality and operability of a system, it is preferred to have everyone experience a +1 state of equal affairs, than having a majority in a +2 pleasure experience whilst a few minorities are jeopardised with a 1 displeasure induced by the inaccessibility of and the inability or refusal to adapt within changing systems.

What is unique about the working outlined in this project is the bringing together of a systemic approach and a method for imbedding data into an interrelated network. Moreover, the possible testing and verification of a systemic approach to UX are made further possible by way of theoretical discussions surrounding an integrative, interdisciplinary utilisation of contemporary philosophical revisions of consequentialism. At once, this integrative and interrelated approach to transdisciplinary research and design practice is interpreted into our working with personas and their cohabiting of journey maps. Particularly, the bringing together of personas within an interdependent socio-technical network, paralleling the convergence of divergent theoretical disciplines in this paper, opens up common spaces for getting on together, between theory and practice. 
Following the philosophical perspective in this paper, this would mean that rail systems should accommodate all travelling members of the public in the attempt to minimise displeasure. This may be done via preserving legacy systems for ticket validation, seat reservation and passenger information, for example presenting inclusive alternatives that do not require a smartphone such as staffed validation, last-minute paper reservations and platform passenger information displays. To run parallel systems will certainly present financial implications and may not be the ideal situation in terms of efficiency, but would accommodate for those who for a number of reasons are unable to use the proposed technologies. This approach could minimise resistance, ensure functionality and prevent a minority using up all resources of the system (Feeny et al., 1990; Hardin, 1968).

What is suggested in this research is a revaluation of goals, expanding upon how research determines what the overall goals of a system are, and how individuals' interests can be reconciled within the design of a system. A method to achieve this consideration lies within personas and their correspondent journey maps, as paradigmatic of a larger pool of users, but with a new, united and shared, perspective. Systems theory has been introduced to some elements of engineering, such as systems architecture that examines the interconnection between software and hardware. As of yet though, UX research could adopt more of this thinking and find ways within their own parameters for verifying a systemic balance between individuals. Unlike other spheres of design, UX is unique for its focus and choice of direction being taken from human users. With personas, these users can be reduced and condensed. With customer journey maps, the multiple touchpoints with services can be isolated and evaluated. The system dynamics and resultant guidance towards designing for systemic cohesion should theoretically also be available. Knowing these components, we deployed research attuned to elements of psychological systems theory and especially the kind of systemic therapy used in family counselling (Kerr, 1981). By mapping the personas as a cast 
of characters, much like a familial unit within a session, workshopping methods were employed to flesh out understanding and manifest ideas of systemic, circular interrelations.

Formal methods to categorise and code the particularities of user's emotional and cultural ideas can be performed under "a value-oriented and culturally informed approach to design" (Pereira and Baranauskas, 2015, p. 71). Somewhat differently in the current research, however, the focus lies in reinventing the initial perceptions and approaches of designers, as well as the final stages of data presentation. Whilst initial steps included taking into account surrounding philosophy and relevant contemporary revisions of utilitarianism, these sentiments are translated into a specific alteration of method that seeks to bring together, both in unity and contrast, data gathered from users. The desire is to paint as much of a systemic picture as possible, to present the data in such a way that it maximally accommodates the diversity of individual's cultural and social needs. This research proposes a systemic framework and thus seeks to gather, handle and present data that most accurately works within all possible particularities of different cultural and social needs to unify them and produce the most efficient and pleasurable shared systemic network of user experiences.

\section{Limitations and future work}

Our multidisciplinary research combined quantitative and qualitative data collection methods, and we acknowledge that there are limitations in both. We used a single item, 5point smiley-face scale for measuring affect in relation to train journeys. Usually, quantitative research uses multi-item Likert scales, which are subsequently validated via statistical analysis to show power of each item and internal consistency. The quantitative data captured during this research was used for formatting the original average journey maps and for the hypothetical application of personas to journey maps, although in both cases, the data was more so qualitatively informed by questionnaire responses and interview discussions. The smiley faces on the journey map exercises were primarily intended to probe interviewees' 
recollections and prompt initial discussion. Through these discussions, the possible variable understandings of affective levels between participants were also worked through by way of conversation and questions that were informed by, but did not stay fixed within, the context of the smiley-scale responses.

It is understood that qualitative data analysis can be subjective and down to the interpretation of the researchers (Long and Johnson, 2000), and the use of personas has limitations of its own in relation to relevance and validity (Chapman and Milham, 2006) or for being stereotypical (Turner and Turner, 2011). To minimise subjectivity and biases, part of the data was examined by a second researcher to provide cross-researcher reliability. An additional strategy was triangulation, targeting the phenomena from two points of view. Through the combination of interviews and questionnaires, we improved the chances of our results being a reasonable representation of the attitudes, needs and behaviours of the sample.

Another limitation inherent to qualitative methods is that participants are often required to recall and give their perceptions about past events. We acknowledge that our interviews were performed with employees of a university divorced from context in terms of time and location. To facilitate the recollection of train journeys we used cultural probes and prompts such as journey maps and ranking scales to improve the validity and accuracy of our methodology. Furthermore, part of the data came from questionnaires given to train passengers in loco, therefore these participants could describe their perceptions about crucial incidents of interaction as these were unfolding.

Although limited in industrial application, the exercise with personas and journey maps presented here worked for the aim and purpose of this article. Not only were they intended to convey goals and needs of individuals within a system, they were also engineered and manipulated to bring about a wider ideal of realising systemic relations and the complex interdependencies in socio-technical networks. Through a study of systemic practices in other 
disciplines, especially psychology and psychotherapy, personas became signifiers not just of their own needs but the dynamics and resultant directives to maximise the efficiency of a system. As well as providing narratives to each persona on their journey maps, methods were taken to workshop them with consortium members in order to highlight circular thinking and foster respect for interrelations required for designs to more appropriately respond to not just individual goals, but also systemic needs. We recognise that this research would benefit from future work to refine and validate our methodology, specifically to include questionings about relations between passengers within the spaces and scenarios characterised by the railways, to further accredit the proposed interdependencies.

\section{Conclusion}

Containing some methodical description, this research triggered wider philosophical interrogation as to the use, coherency and viability of the use of personas and customer journey maps - common methods of presenting research and influencing design. Personas appear as paradigmatic of the overall UX research mandate, both expressing interests in realising goals and fulfilling these, inducing maximal pleasure for individual users. Questions were also placed on customer journey maps and their fit to represent overall affects. There is the wish here to argue for the use of personas alongside customer journey maps, which when married together further help cement and justify the emergence of new, systemically-oriented perspectives that originate from philosophical theories in order to propose new ethical and shared-experience dimensions of UX.

It is the philosophical responsibility of any designer or researcher to think more considerately and diversely toward individuals' varied, yet interactive and ultimately accumulative experiences of a shared system. A more systemic approach, minimising displeasures at the expense of reducing the pleasures of others, facilitates an overall experiential system that levels out each and every individuals' satisfactory experiences. Our 
work, embodying this principle, primarily demonstrated a necessity to reformulate UX research in line with contemporary reformulations of philosophy. Our resultant findings enforce and underline justificatory good in thinking and designing with a view toward systemic UX and user satisfaction; the dependent and interconnected propositional pleasures of individuals that differently occupy yet similarly rely on the efficiency of the same system. Concluding points of this paper relate more widely towards the marriage of experiential engineering and philosophy. The attempt made here was to work in broader frameworks to accommodate more comprehensive user requirements, therefore better representing a system as a whole.

\section{Implications for design}

This paper presented a criticism of customer journey maps as a tool to represent average affect at specific points of interaction with product and services. These maps should at least incorporate different personas and scenarios to better inform the design of innovative systems. Additional critique is placed on personas and the tendency to design for one person (or a primary persona). Since technologies are intended to innovate public services, a rather holistic, inclusive and systems-based approach should be adopted. This research follows the use of personas and customer journey maps in parallel, incorporating a systemic approach during a service design project. By doing so, the designer will have the means for workshopping all the user personas back into combined customer journey maps. This process indicates how users are affected at each touchpoint, and where the designer can highlight the interactions that are causing displeasure.

A focus on journey mapping might well be transposed to the research and design process itself. For example, the Design Council's Double Diamond Model (2005), outlines a route from discovery to delivery for researchers to follow, which identifies touchpoints defining and developing - which can be returned to. Following and building upon established 
methods of design thinking and service design (Stickdorn and Schneider, 2010), it is further suggested that systemic UX design is uniquely beneficial when designing improvements in an intersubjective process or system. In this way, the present project proposes an imbedded approach to research and design grounded in the integrated perspectives and shared spaces of socio-technical systems.

Working with personas allows for the cutting through and breaking down of intersubjective borders between stakeholders within a system. Whilst empirically grounded in the data, personas present a tool for bringing together the experiences and positions of all users, researchers and business shareholders. Fictionalised characters and narratives engage questioning, creative and speculative understanding; whilst each individual is themselves engaged, the sharing in this engagement between users and the sharing in original data between the personas emphasises the circularity and open-ended feedback loops that structure interconnected systems. A successful and rounded systemic UX design approach (Figure 4) should remain open-ended; our personas may live in on through further related work, their narratives should continue being thought for as long as the system is in place.

We still believe that innovative technologies should be incorporated into services such as rail transport to bring about needed modernisation. However, this research is specifically concerned with a holistic and optimally functioning socio-technological system. We may see in the future that technology eliminates the need for crew interaction, therefore 'designing out' an enjoyable and essential part of current journeys for a number of passengers. Reducing their displeasure is preferential because a neutral experience for many is still more functioning, more efficient than the chance that even one individual might suffer displeasure to the degree that they would be unable to efficiently operate in the wider system, with the potential to become a 'spanner in the works' and negate the benefits proposed in the first place. This systemic approach not only generates more interrelated and shared conceptions of 
UX and business ethics, but also provides solution-focused grounding in data that objectively presents tangible means of improving the shared wellbeing of users and the efficiency of the systems they occupy.

\section{Acknowledgements}

The first and second authors contributed equally to the production and revision of this manuscript. The authors would like to thank the anonymous reviewers for their thorough comments, which helped improve the quality of this publication. This research is performed as part of the "CLoSeR: Customer Loyalty and Dynamic Seat Reservation System" project, funded by RSSB / Innovate UK (Grant No 102483). This project was selected through the competition 'Enhancing Customer Experience in Rail'.

\section{References}

Aceves-González, C., Cook, S., May, A., 2015. Bus use in a developing world city: Implications for the health and well-being of older passengers. J. Transp. Heal. 2, 308316. doi:10.1016/j.jth.2015.04.001

Aceves-González, C., May, A., Cook, S., 2016. An observational comparison of the older and younger bus passenger experience in a developing world city. Ergonomics 59, 840-850. doi:10.1080/00140139.2015.1091513

Basart, J.M., Farrús, M., Serra, M., 2015. New ethical challenges for today engineering and technology. Telemat. Informatics 32, 409-415. doi:10.1016/j.tele.2014.05.008

Bateson, G., 1972. Steps to an Ecology of Mind, 1st ed, Steps to an Ecology of Mind. Chandler, San Francisco. doi:10.7208/chicago/9780226924601.001.0001

Bentham, J., 1996. The Collected Works of Jeremy Bentham: An Introduction to the Principles of Morals and Legislation. Oxford University Press, Oxford, UK. doi:10.1093/actrade/9780198205166.book.1

Blommaert, J., 2004. Workshopping: Professional Vision, Practices and Critique in Discourse Analysis. Academia Press, Gent, Belgium.

Blythe, M., Reid, J., Wright, P., Geelhoed, E., 2006. Interdisciplinary criticism: Analysing the experience of riot! a location-sensitive digital narrative. Behav. Inf. Technol. 25, 127-139. doi:10.1080/01449290500331131

Braun, V., Clarke, V., 2006. Using thematic analysis in psychology. Qual. Res. Psychol. 3, 77-101. doi:10.1191/1478088706qp063oa

Broberg, O., Andersen, V., Seim, R., 2011. Participatory ergonomics in design processes: The role of boundary objects. Appl. Ergon. 42, 464-472. doi:10.1016/j.apergo.2010.09.006

Burrows, A., Gooberman-Hill, R., Coyle, D., 2015. Empirically derived user attributes for the design of home healthcare technologies. Pers. Ubiquitous Comput. 19, 1233-1245. doi:10.1007/s00779-015-0889-1 
Camacho, T.D., Foth, M., Rakotonirainy, A., 2013. Pervasive Technology and Public Transport: Opportunities Beyond Telematics. IEEE Pervasive Comput. 12, 18-25. doi:10.1109/MPRV.2012.61

Chapman, C.N., Milham, R.P., 2006. The Personas' New Clothes: Methodological and Practical Arguments against a Popular Method. Proc. Hum. Factors Ergon. Soc. Annu. Meet. 50, 634-636. doi:10.1177/154193120605000503

Cooper, A., 1999. The inmates are running the asylum, 1st ed. Sams, Indianapolis, IN.

Design Council, 2005. A study of the design process [WWW Document]. Br. Des. Counc. URL

https://www.designcouncil.org.uk/sites/default/files/asset/document/ElevenLessons_Des ign_Council (2).pdf (accessed 6.29.20).

Feeny, D., Berkes, F., McCay, B.J., Acheson, J.M., 1990. The Tragedy of the Commons: Twenty-two years later. Hum. Ecol. 18, 1-19. doi:10.1007/BF00889070

Fei, T., de Joux, N., Kefalidou, G., D’Cruz, M., Sharples, S., 2016. Towards Understanding Information Needs and User Acceptance of Mobile Technologies to Improve Passenger Experience in Airports, in: Proceedings of the European Conference on Cognitive Ergonomics - ECCE '16. ACM Press, New York, New York, USA, pp. 1-4. doi: $10.1145 / 2970930.2970938$

Feldman, F., 1997. Utilitarianism, hedonism, and desert: Essays in moral philosophy. Cambridge University Press, Cambridge, UK.

Foth, M., Schroeter, R., 2010. Enhancing the experience of public transport users with urban screens and mobile applications. Proc. 14th Int. Acad. MindTrek Conf. Envisioning Futur. Media Environ. - MindTrek '10 33. doi:10.1145/1930488.1930496

Friman, M., Gärling, T., Ettema, D., Olsson, L.E., 2017. How does travel affect emotional well-being and life satisfaction? Transp. Res. Part A Policy Pract. 106, 170-180. doi:10.1016/j.tra.2017.09.024

Goodwin, K., 2009. Designing for the Digital Age: How to Create Human-Centered Products and Services. John Wiley \& Sons.

Groff, J., Boucheix, J.M., Lowe, R.K., Argon, S., Saby, L., Alauzet, A., Paire-Ficout, L., 2014. Don't miss your train! Just follow the computer screen animation: Comprehension processes of animated public information graphics. Comput. Human Behav. 30, 206221. doi:10.1016/j.chb.2013.08.010

Grudin, J., 2006. Why personas work: the psychological evidence, in: The Persona Lifecycle: Keeping People in Mind. Morgan Kaufmann, pp. 642-663.

Haines, V., Mitchell, V., 2014. A persona-based approach to domestic energy retrofit. Build. Res. Inf. 42, 462-476. doi:10.1080/09613218.2014.893161

Hardin, G., 1968. The Tragedy of the Commons. Sci. Mag. 162, 1243-1248. doi:10.1126/science.162.3859.1243

Hassenzahl, M., 2010. Experience Design: Technology for All the Right Reasons. Synth. Lect. Human-Centered Informatics 3, 1-95. doi:10.2200/S00261ED1V01Y201003HCI008

Hassenzahl, M., Tractinsky, N., 2006. User experience - A research agenda. Behav. Inf. Technol. 25, 91-97. doi:10.1080/01449290500330331

Hutchinson, H., Mackay, W., Westerlund, B., Bederson, B.B., Druin, A., Plaisant, C., Beaudouin-Lafon, M., Conversy, S., Evans, H., Hansen, H., Roussel, N., Eiderbäck, B., 2003. Technology Probes: Inspiring Design for and with Families. pp. 17-24. doi:10.1145/642611.642616

Jain, J., Lyons, G., 2008. The gift of travel time. J. Transp. Geogr. 16, 81-89. doi:10.1016/j.jtrangeo.2007.05.001

Jupe, R., Funnell, W., 2017. 'A highly successful model'? The rail franchising business in 
Britain. Bus. Hist. 59, 844-876. doi:10.1080/00076791.2016.1270268

Jüttner, U., Schaffner, D., Windler, K., Maklan, S., 2013. Customer - service experiences:

Developing and applying a sequential incident laddering technique. Eur. J. Mark. 47, 738-769. doi:10.1108/03090561311306769

Karahanna, E., Straub, D.W., Chervany, N.L., 1999. Information Technology Adoption Across Time: A Cross-Sectional Comparison of Pre-Adoption and Post-Adoption Beliefs. MIS Q. 23, 183. doi:10.2307/249751

Kefalidou, G., Cruz, M.D., Sharples, S., De Lille, C., Frangakis, N., Ottens, R., Grosmann, R., Marcelino, R., Lütjens, K., Löwa, S., Shaw, E., Nardini, A., Santema, S., D 'cruz, M., Sharples, S., De Lille, C., Frangakis, N., Ottens, R., Grosmann, R., Marcelino, R., Lütjens, K., Löwa, S., Shaw, E., Nardini, A., Santema, S., 2016. Passengers' Requirements for developing a Passenger - Centred Infrastructure to Enhance Travel Experiences at Airports, in: Conference Proceedings of the Chartered Institute of Ergonomics and Human Factors. Daventry, UK, pp. 1-6.

Kerr, M.E., 1981. Family systems theory and therapy, in: Alans S. Gurman, David P Kniskern (Eds.), Handbook of Family Therapy. Routledge, London, pp. 226-264.

Kuniavsky, M., Goodman, E., Moed, A., 2012. Observing the User Experience: A Practitioner's Guide to User Research, 2nd ed. Morgan Kaufmann.

Long, T., Johnson, M., 2000. Rigour, reliability and validity in qualitative research. Clin. Eff. Nurs. 4, 30-37. doi:10.1054/cein.2000.0106

Lyons, G., Jain, J., Weir, I., 2016. Changing times - A decade of empirical insight into the experience of rail passengers in Great Britain. J. Transp. Geogr. 57, 94-104. doi:10.1016/j.jtrangeo.2016.10.003

Mackrill, J., Marshall, P., Payne, S.R., Dimitrokali, E., Cain, R., 2017. Using a bespoke situated digital kiosk to encourage user participation in healthcare environment design. Appl. Ergon. 59, 342-356. doi:10.1016/j.apergo.2016.08.005

Maguire, M., 2001. Methods to support human-centred design. Int. J. Human-Computer Stud. 55, 587-634. doi:10.1006/ijhc.2001.0503

Marshall, R., Cook, S., Mitchell, V., Summerskill, S., Haines, V., Maguire, M., Sims, R., Gyi, D., Case, K., 2015. Design and evaluation: End users, user datasets and personas. Appl. Ergon. 46, 311-317. doi:10.1016/j.apergo.2013.03.008

McCartney, S., Stittle, J., 2017. 'A Very Costly Industry': The cost of Britain's privatised railway. Crit. Perspect. Account. 49, 1-17. doi:10.1016/j.cpa.2017.04.002

Miaskiewicz, T., Kozar, K.A., 2011. Personas and user-centered design: How can personas benefit product design processes? Des. Stud. 32, 417-430. doi:10.1016/j.destud.2011.03.003

Mill, J.S., 1864. Utilitarianism. Longman, Green, Longman, Roberts and Green, London, UK.

Nozick, R., 2013. Anarchy, State, and Utopia. Basic Books, New York, NY, USA.

Oliveira, L., Birrell, S., Cain, R., 2020. How technology can impact customer-facing train crew experiences. Ergonomics 0, 1-15. doi:10.1080/00140139.2020.1772377

Oliveira, L., Bradley, C., Birrell, S., Davies, A., Tinworth, N., Cain, R., 2017. Understanding passengers' experiences of train journeys to inform the design of technological innovations, in: Re: Research - the 2017 International Association of Societies of Design Research (IASDR) Conference. Cincinnati, Ohio, USA, pp. 838-853. doi: $10.7945 / \mathrm{C} 2 \mathrm{R} 388$

Oliveira, L., Bradley, C., Birrell, S., Tinworth, N., Davies, A., Cain, R., 2018. Using Passenger Personas to Design Technological Innovation for the Rail Industry, in: INTSYS - Intelligent Transport Systems - From Research and Development to the Market Uptake. Springer, Helsinki, Finland, pp. 67-75. doi:10.1007/978-3-319-93710- 


\section{8}

Oliveira, L., Bruen, C., Birrell, S., Cain, R., 2019. What passengers really want: Assessing the value of rail innovation to improve experiences. Transp. Res. Interdiscip. Perspect. 1, 1-9. doi:10.1016/j.trip.2019.100014

Oliveira, L., Mitchell, V., May, A., 2016. Reducing temporal tensions as a strategy to promote sustainable behaviours. Comput. Human Behav. 62, 303-315. doi:10.1016/j.chb.2016.04.004

Oliveira, L.C., Birrell, S., Cain, R., 2020. Journey mapping from a crew's perspective: Understanding rail experiences. Appl. Ergon. 85, 103063. doi:10.1016/j.apergo.2020.103063

Oliveira, L.C., Fox, C., Birrell, S., Cain, R., 2019. Analysing passengers' behaviours when boarding trains to improve rail infrastructure and technology. Robot. Comput. Integr. Manuf. 57, 282-291. doi:10.1016/j.rcim.2018.12.008

ORR, 2015. Statistical releases - Passenger rail usage [WWW Document]. Off. Rail Road. URL http://orr.gov.uk/statistics/published-stats/statistical-releases (accessed 1.29.16).

Peña Miñano, S., Kirkwood, L., Court, S., Farnsworth, M., Orlovs, I., Shehab, E., Tinworth, N., Miñano, S.P., Kirkwood, L., Court, S., Farnsworth, M., Shehab, E., Tinworth, N., Peña Miñano, S., Kirkwood, L., Court, S., Farnsworth, M., Orlovs, I., Shehab, E., Tinworth, N., 2017. A review of digital wayfinding technologies in the transportation industry, in: Advances in Transdisciplinary Engineering. IOS Press, Greenwich, London, UK, pp. 207-212. doi:10.3233/978-1-61499-792-4-207

Pereira, R., Baranauskas, M.C.C., 2015. A value-oriented and culturally informed approach to the design of interactive systems. Int. J. Hum. Comput. Stud. 80, 66-82. doi:10.1016/j.ijhcs.2015.04.001

Posner, J., Russell, J.A., Peterson, B.S., 2005. The circumplex model of affect: An integrative approach to affective neuroscience, cognitive development, and psychopathology. Dev. Psychopathol. 17, 715-734. doi:10.1017/S0954579405050340

Santana, F.E., Cardoso, C.C., Ferreira, M.G.G., Catapan, M.F., Montanha, I.R., Forcellini, F.A., 2018. Towards a more inclusive service development process for the wider population. Des. Stud. 55, 146-173. doi:10.1016/j.destud.2017.10.003

Stein, A., Ramaseshan, B., 2016. Towards the identification of customer experience touch point elements. J. Retail. Consum. Serv. 30, 8-19. doi:10.1016/j.jretconser.2015.12.001

Stickdorn, M., Schneider, J., 2010. This is service design thinking. BIS Publishers, Amsterdam, The Netherlands.

Transport Committe, 2016. The future of rail: Improving the rail passenger experience [WWW Document]. Transp. Comm. URL https://www.publications.parliament.uk/pa/cm201617/cmselect/cmtrans/64/6402.htm (accessed 5.4.17).

Transport Focus, 2014. The passenger experience - the full research report [WWW Document]. URL http://www.transportfocus.org.uk/research/publications/the-passengerexperience-the-full-research-report

Tseng, T.H., Lee, C.T., 2018. Facilitation of consumer loyalty toward branded applications: The dual-route perspective. Telemat. Informatics 35, 1297-1309. doi:10.1016/j.tele.2018.03.002

Turner, P., Turner, S., 2011. Is stereotyping inevitable when designing with personas? Des. Stud. 32, 30-44. doi:10.1016/j.destud.2010.06.002

van Hagen, M., Bron, P., 2014. Enhancing the Experience of the Train Journey: Changing the Focus from Satisfaction to Emotional Experience of Customers. Transp. Res. Procedia 1, 253-263. doi:10.1016/j.trpro.2014.07.025

Venkatesh, V., Thong, J., Xu, X., 2012. Consumer Acceptance and Use of Information 
Technology: Extending the Unified Theory of Acceptance and Use of Technology. Manag. Inf. Syst. Q.

Wardman, M., Murphy, P., 2015. Passengers' valuations of train seating layout, position and occupancy. Transp. Res. Part A Policy Pract. 74, 222-238. doi:10.1016/j.tra.2015.01.007

Wockatz, P., Schartau, P., 2015. Traveller Needs and UK Capability Study [WWW Document]. Transp. Syst. Catapult. URL https://ts.catapult.org.uk/traveller-needs-anduk-capability-study

Zeithaml, V.A., Berry, L.L., Parasuraman, A., 1993. The Nature and Determinants of Customer Expectations of Service. J. Acad. Mark. Sci. 21, 1-12. doi:10.1177/0092070393211001 